\title{
Craniopharyngioma adherence: a comprehensive topographical categorization and outcome-related risk stratification model based on the methodical examination of 500 tumors
}

\author{
Ruth Prieto, MD, PhD, ${ }^{1}$ José María Pascual, MD, PhD, ${ }^{2}$ Maria Rosdolsky, MD, ${ }^{3}$ \\ Inés Castro-Dufourny, MD, PhD, ${ }^{4}$ Rodrigo Carrasco, MD, ${ }^{5}$ Sewan Strauss, MD, ${ }^{6}$ and \\ Laura Barrios, BS $^{7}$
}

1'Department of Neurosurgery, Puerta de Hierro University Hospital; 2Department of Neurosurgery, La Princesa University Hospital; ${ }^{4}$ Department of Endocrinology, Hospital del Sureste; ${ }^{5}$ Department of Neurosurgery, Ramón y Cajal University Hospital; and ${ }^{7}$ Statistics Department, Computing Center, C.S.I.C., Madrid, Spain; ${ }^{6}$ School of Medicine, Technische Universität, Dresden, Germany; and ${ }^{3}$ ndependent Medical Translator, Jenkintown, Pennsylvania

OBJECTIVE Craniopharyngioma (CP) adherence strongly influences the potential for achieving a radical and safe surgical treatment. However, this factor remains poorly addressed in the scientific literature. This study provides a rational, comprehensive description of CP adherence that can be used for the prediction of surgical risks associated with the removal of these challenging lesions.

METHODS This study retrospectively analyzes the evidence provided in pathological, neuroradiological, and surgical $\mathrm{CP}$ reports concerning 3 components of the CP attachment: 1) the intracranial structures attached to the tumor; 2) the morphology of the adhesion; and 3) the adhesion strength. From a total of $1781 \mathrm{CP}$ reports published between 1857 and 2016, a collection of 500 CPs providing the best information about the type of CP attachment were investigated. This cohort includes autopsy studies $(n=254)$; surgical studies with a detailed description or pictorial evidence of CP adherence $(n=298)$; and surgical CP videos ( $n=61$ ) showing the technical steps for releasing the attachment. A predictive model of CP adherence in hierarchical severity levels correlated with surgical outcomes was generated by multivariate analysis.

RESULTS The anatomical location of the CP attachment occurred predominantly at the third ventricle floor (TVF) (54\%, $n=268)$, third ventricle walls $(23 \%, n=114)$, and pituitary stalk $(19 \%, n=94)$. The optic chiasm was involved in $56 \%$ $(n=281)$. Six morphological patterns of CP attachment were identified: 1) fibrovascular pedicle (5.4\%); 2 ) sessile or patch-like (21\%); 3) cap-like (over the CP top, 14\%); 4) bowl-like (around the CP bottom, 13.5\%); 5) ring-like (encircling central band, 19\%); and 6) circumferential (enveloping the entire CP, 27\%). Adhesion strength was classified in 4 grades: 1) loose (easily dissectible, 8\%); 2) tight (requires sharp dissection, 32\%); 3) fusion (no clear cleavage plane, $40 \%$ ); and 4) replacement (loss of brain tissue integrity, 20\%). The types of CP attachment associated with the worst surgical outcomes are the ring-like, bowl-like, and circumferential ones with fusion to the TVF or replacement of this structure $(p<0.001)$. The CP topography is the variable that best predicts the type of CP attachment $(p<0.001)$. Ring-like and circumferential attachments were observed for CPs invading the TVF (secondary intraventricular CPs) and CPs developing within the TVF itself (infundibulo-tuberal CPs). Brain invasion and peritumoral gliosis occurred predominantly in the ring-like and circumferential adherence patterns $(p<0.001)$. A multivariate model including the variables CP topography, tumor consistency, and the presence of hydrocephalus, infundibulo-tuberal syndrome, and/or hypothalamic dysfunction accurately predicts the severity of CP attachment in $87 \%$ of cases.

CONCLUSIONS A comprehensive descriptive model of CP adherence in 5 hierarchical levels of increased severity—mild, moderate, serious, severe, and critical—was generated. This model, based on the location, morphology, and

ABBREVIATIONS CHAID = chi-square automatic interaction detection; $\mathrm{CP}=$ craniopharyngioma; $\mathrm{HICP}=$ high intracranial pressure; $\mathrm{PG}=$ pituitary gland; $\mathrm{PS}=$ pituitary stalk; TVF = third ventricle floor; $3 \mathrm{~V}=$ third ventricle.

SUBMITTED July 28, 2016. ACCEPTED September 23, 2016

INCLUDE WHEN CITING DOI: 10.3171/2016.9.FOCUS16304. 


\begin{abstract}
strength of the attachment can be used to anticipate the surgical risk of hypothalamic injury and to plan the degree of removal accordingly.

https://thejns.org/doi/abs/10.3171/2016.9.FOCUS16304
\end{abstract}

KEY WORDS craniopharyngioma; tumor adherence; hypothalamus; surgical outcome; third ventricle; pituitary gland; brain invasion; gliosis

\begin{abstract}
These congenital epithelial tumors $[\ldots]$ so definitely adhere to the adjacent structures neighboring on their place of origin, it is rarely possible to shell them out of their bed without the production of serious secondary symptoms.
\end{abstract}

$$
\text { - Harvey W. Cushing }{ }^{9}
$$

Craniopharyngiomas (CPs) remain a surgical challenge. A factor of critical importance that determines the feasibility of a safe, radical removal of each $\mathrm{CP}$ is the tumor's adherence to the contiguous vital structures, mainly the hypothalamus and the vessels of the circle of Willis. 4,12,25,29,33,51,53 An extensive and strong CP attachment to the adjacent brain tissue frequently justifies incomplete resection, as stated by experts..$^{10,14,56,59}$ Nevertheless, an adequate definition of $\mathrm{CP}$ adherence is lacking in the medical literature, and the influence of this variable on surgical outcome has not been thoroughly investigated in large surgical series. Most experts on CP surgery simply mention the risks associated with attempts to resect strong adhesions present between the tumor capsule and the adjacent hypothalamus. ${ }^{14,25,39,59}$ However, a clear and meaningful description of the term "strong adherence"-a subjective, overly imprecise variable-is not provided in any of these studies. As a factor essential for interpretation of surgical results, $\mathrm{CP}$ adherence should not remain a subjective concern whose definition depends mainly on the neurosurgeon's personal interpretation.

A sound, common classification scheme of $\mathrm{CP}$ adherence patterns is necessary, one that can serve as a useful tool to predict the risks of surgery, should a radical removal of a CP be attempted. Our research involved the thorough examination of pathological and surgical evidence of CP adherence in a cohort of 500 well-described tumors reported in the medical literature. The major objective of this study was to describe and analyze the variable $\mathrm{CP}$ adherence in a systematic, categorical way. In addition, we investigated the correlation between increasing levels of tumor adherence severity and the postoperative outcome, with the aim of discriminating between CPs that are lowor high-risk lesions, according to the location, extent, and strength of their adherence.

\section{Methods}

\section{Database Generation and Case Selection Criteria}

We conducted a systematic search of highly detailed $\mathrm{CP}$ cases reported in the scientific literature between 1857 and 2016. A full description of our search and the list of medical libraries explored in the US and several European countries can be found in our group's previous papers. ${ }^{29,31,32,35,44}$ Our initial database included 1781 scientific documents. From these, a final cohort of $500 \mathrm{CPs}$ was selected (see Supplemental Table and Reference List), in accordance with the following inclusion criteria: 1) the $\mathrm{CP}$ diagnosis was confirmed pathologically, and reliable anatomical information regarding the tumors' relationship with surrounding structures was provided; 2) recurrent cases were excluded from the analysis; 3 ) for nonsurgically treated CPs reported in autopsy studies, we selected preferentially the ones providing high-quality pictures or illustrations of the brain specimen with the tumor in situ; 4) for CPs reported in surgical studies, we included cases providing a detailed description of tumor relationships to surrounding structures, preferably those illustrating the location of $\mathrm{CP}$ adherence with surgical images as well as those providing a complete clinical history and pre- and/or postoperative MRI scans; and 5) surgical videos showing the complete sequence of technical steps for releasing the $\mathrm{CP}$ attachments were also included.

\section{Variables Analyzed and Topographical Classification of Tumors}

The variables analyzed and categorized for each case were as follows: patient age and sex; presenting symptoms; CP topography, shape, size, and consistency; tumor histological findings; presence of calcifications; peritumoral gliosis and macroscopic or microscopic brain invasion; intracranial structures attached to the tumor; extent and degree of CP attachment; type of surgical approach used; degree of tumor removal; postoperative outcome; and evidence of hypothalamic injury as the cause of postoperative death.

The clinical symptoms present in each patient were grouped into the following syndromes: ${ }^{5}$ 1) high intracranial pressure (HICP) - headache accompanied by vomiting, papilledema, and/or hydrocephalus; 2) chiasmal syndrome-loss of visual acuity or visual field defect; 3) pituitary syndrome-symptoms of hypopituitarism including isolated sexual disturbances, hair loss, skin atrophic alterations, and asthenia of unknown origin; 4) infundibulo-tuberal syndrome-Fröhlich's syndrome (sexual infantilism and obesity), changes in eating behavior, diabetes insipidus, or sleep disturbances (in particular abnormal diurnal somnolence); 5) hypothalamic syndrome-psychiatric, behavioral, or emotional alterations including Korsakofflike memory impairment, abnormal changes in body temperature, gait disturbances, extrapyramidal symptoms, or sphincter incontinence; or 6) neurological disturbancesincluding seizures and sensory/motor deficits affecting either cranial nerves (except the optic nerves) or any of the limbs.

Tumor size was categorized into 3 groups - small $(\leq 2.5$ $\mathrm{cm})$; medium-large $(2.6-4.9 \mathrm{~cm})$; and giant $(\geq 5 \mathrm{~cm})$. The 
CP shape was classified into 5 categories-round; elliptical; multilobulated; pear-like; and dumbbell. Tumor consistency was classified into 5 types: pure solid; pure cystic; mixed heterogeneous solid-cystic; upper cystic-basal solid lesion; and cystic lesion with a solid cauliflower-like excrescence from its inner lining.

Based on our previously published classification scheme for CP topography, ${ }^{28,29,31,32,37}$ the 500 CPs included in this cohort were classified into 5 major categories: 1) sellar-suprasellar CPs, which occupy exclusively the sellar and/or suprasellar compartments; 2) suprasellar-pseudointraventricular CPs, which occupy the suprasellar cistern and cause an upward displacement of the third ventricle floor (TVF); 3) secondary intraventricular CPs, which extend from the sellar and/or suprasellar compartments into the third ventricle (3V), after breaking through the TVF; 4) infundibulo-tuberal or not strictly intraventricular CPs-tumors developed in the TVF itself that replace the infundibulum and the tuber cinereum as they grow; and 5) strictly intraventricular CPs, which grow within the $3 \mathrm{~V}$, above an intact TVF.

\section{Criteria for CP Adherence Definitions}

The CP adherence was defined according to 3 independent variables or components of the attachment for each case (see Supplemental Table): 1) the anatomical structures attached to the tumor; 2) the morphology and extent of the attachment; and 3) the degree or strength of the attachment between the anatomical structure and the tumor. The anatomical structures with a proven attachment to the lesion were grouped into the following categories: 1) sella-pituitary gland (PG): any attachment below the plane of the diaphragma sellae, including the junction of the pituitary stalk (PS) with the PG; 2) PS-outer infundibulum: attachment at the solid portion of the stalk and/ or the outer aspect of the infundibulum-tuber cinereum; 3) TVF: attachment involving the whole thickness of the infundibulum/tuber cinereum; 4) TVF and walls (TVF$3 \mathrm{~V})$ : the attachment involves the neural layer of the TVF and a limited part or the entire extension of one or both $3 \mathrm{~V}$ walls; 5) $3 \mathrm{~V}$ lining: the attachment only involves the ependymal layer of the $3 \mathrm{~V}$; and 6) global attachment: in which all the structures listed above are involved. In addition, $\mathrm{CP}$ attachments to the optic chiasm, optic nerves, the circle of Willis, and the brainstem were considered for each case.

The extent of the CP attachment was categorized into 6 major morphological patterns: 1) pedicle: the attachment consists of a narrow fibrovascular stem; 2) sessile: a wider patch of the tumor surface is attached to the anatomical structure; 3) cap-like: wide attachment between the upper third to upper half portion of a tumor pushing the TVF upward; 4) bowl-like: wide attachment between the lower third to half portion of a tumor pushing the contiguous structures downward; 5) ring-like: the attachment encircles the center of the tumor surface as a band; and 6) circumferential: the attachment involves most of the tumor surface, usually as a very thin layer of nervous-gliotic tissue, like wrapping paper.

Finally, the degree of the attachment or adhesion strength was classified into 4 categories. 1) Loose-dis- sectible adherence: the tumor can be easily separated from the attached structure by gentle tugging or by blunt dissection, preserving the integrity of the anatomical structure. 2) Tight adherence: separation of the tumor requires the use of sharp dissection to preserve the anatomical integrity of the structure involved. Blunt dissection would lead to petechial hemorrhages or contusive injury within neural tissue due to ependymal or pial disruptions. 3) Fusion: the $\mathrm{CP}$ capsule and the adjacent anatomical structure are fused together along the plane of attachment. No safe cleavage plane for tumor dissection can be identified, and even careful sharp dissection may cause damage to the normal tissue. 4) Replacement: the anatomical structure adhered to the tumor has lost its integrity and is no longer recognizable, because it has been replaced or invaded by the CP.

\section{Postoperative Outcome Assessment}

Postoperative outcome was classified into 4 categories: 1) good: long-term survival without new permanent neurological, hypothalamic, or neuropsychological deficits, including the presence of transitory disturbances; 2) fair: with new permanent but not disabling neurological, hypophyseal, or hypothalamic deficits, including panhypopituitarism, diabetes insipidus, cerebrospinal fistula, or meningitis; 3) poor: symptoms of severe hypothalamic derangement, such as consciousness disturbances, insane behavior, global amnesia, cachexia, hyperthermia, and so on, that considerably impaired the quality of life; and 4) death within the 1st month after surgery.

\section{Statistical Analysis}

Statistical analyses were performed using SPSS software (version 23, IBM Corp.). Frequencies and descriptive statistics on the various categorical variables under study were obtained. Bilateral correlations between pairs of categorical variables were tested using the asymptotic chi-square test or the Monte Carlo exact test. Significance was assumed at a probability value less than 0.05 . The epidemiological, clinical, and pathological variables that were knowable preoperatively and that showed significant bivariate relationships with the nominal variables or components defining $\mathrm{CP}$ adherence (structures attached, morphological pattern of attachment, and adhesion strength) were further investigated with multivariate analysis. For this purpose we first defined 5 levels of increasing adherence severity, by integrating information from the 3 components of $\mathrm{CP}$ adherence. Second, the multivariate chisquare automatic interaction detection (CHAID) method was applied and significance values were adjusted using the Bonferroni method. This hierarchical, stepwise procedure creates a decision tree. At each step it chooses the nominal variable, which shows the strongest independent interaction with the different levels of adherence severity for the tumors included in the previous step. Goodnessof-fit measure for this model was the correct prediction of levels of adherence severity. Next, we investigated the predictive power of adherence severity achieved with the best variable identified by the CHAID method. We used a simple correspondence analysis to describe the relation- 

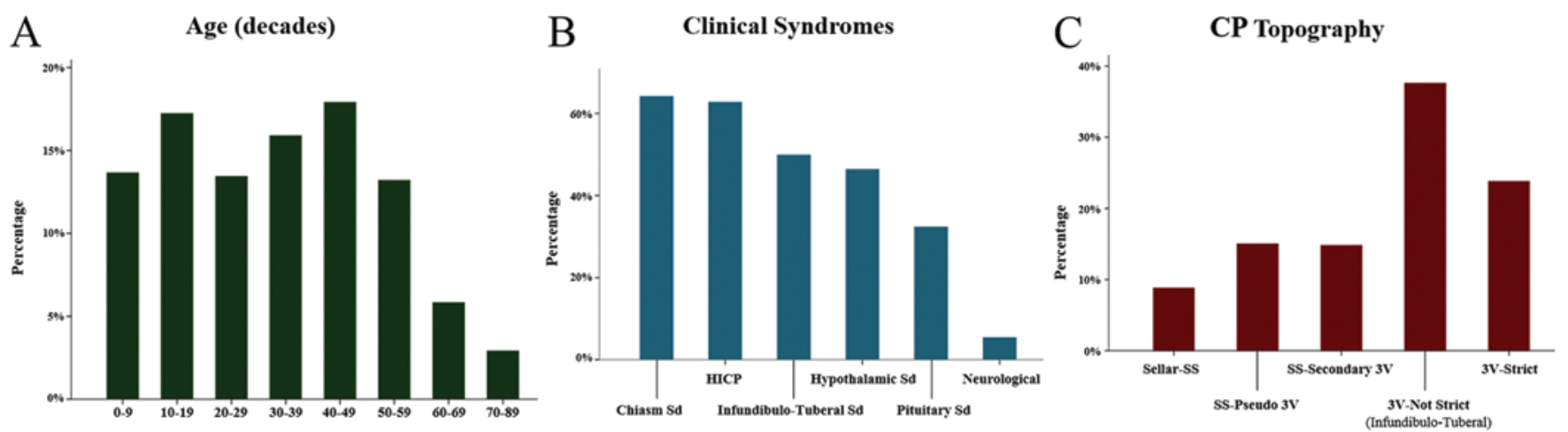

FIG. 1. Epidemiological, clinical, and topographical characterization of the cohort of $500 \mathrm{CPs}$ analyzed in this study. A: Bar graph of age distribution in 447 cases (age unknown in 53 cases). B: Bar graph displaying the distribution of the main clinical syndromes (symptoms known in 425 cases). Sd = syndrome. C: Bar graph showing percentage distribution of CP topographies. Sellar-SS = sellar-suprasellar (8.8\%); SS-Pseudo 3V = suprasellar pseudointraventricular (15\%); SS-Secondary 3V = suprasellar secondary intraventricular (14.8\%); 3V-Not Strict = infundibulo-tuberal or not strictly intraventricular (37.6\%); 3V-Strict = strictly intraventricular $(23.8 \%)$.

ships between this variable and adherence severity in a 2D correspondence table.

\section{Results \\ A Collection of $500 \mathrm{CPs}$ to Investigate Tumor Adherence: Characteristics of the Cohort}

The Supplemental Table presents a summary of the epidemiological and pathological features of the $500 \mathrm{CPs}$ included in this study, as well as the 3 components of tumor adherence analyzed for each case. A rather balanced distribution between the sexes was observed (male/female ratio: 1.19), with 2 incidence peaks - in children and young adults $<20$ years of age $(30 \%)$ and in middle-aged patients between 30 and 49 years (33\%) (Fig. 1A). The distribution of symptoms in the 6 major syndrome categories considered (available in 425 cases) is shown in Fig. 1B. Visual loss and headache were the 2 predominant symptoms, observed in two-thirds of the patients. The high incidence of symptoms related to impairment of the median eminence-infundibulo-tuberal syndrome- $(50 \%)$ or hypothalamic dysfunction (46\%) in this cohort is explained by the high percentage of CPs that developed at the TVF or within the $3 \mathrm{~V}$.

Distribution of CP topographies in this cohort is shown in Fig. 1C. A majority of CPs developed either at the TVF (infundibulo-tuberal area, 37\%; $\mathrm{n}=188$ ) or within the $3 \mathrm{~V}$ $(23 \%, \mathrm{n}=119)$. The rest of the lesions developed originally from the PG-PS complex, beneath the TVF. A roundshaped tumor was the most common morphology observed (48\%). Almost $60 \%$ of the tumors had a medium to large size, from 2.6 to $4.9 \mathrm{~cm}$, and the predominant consistency was mixed solid-cystic (33\%). The adamantinomatous variant was diagnosed in 301 (72\%) of the 416 lesions in which there was a definite histological diagnosis, the squamouspapillary variant was found in 111 of 416 cases (27\%), and the other 4 cases were mixed variants. Evidence for tumor calcifications was confirmed in $64 \%$ of 274 cases. Histological verification of reactive gliosis enveloping the tumor capsule was available in $71 \%$ of 106 studies. Finally, in 51\% of $259 \mathrm{CPs}$, macro- or microscopic tumor invasion of the adjacent brain tissue was observed.

\section{Surgical Procedures and Postoperative Outcome}

Two-thirds of the patients in this cohort had undergone surgical treatment $(\mathrm{n}=338)$. A basal pterional/subfrontal route was used in $40 \%$. The translamina terminalis approach was used in $16 \%$ of the cases. Upper transcallosal or transcortical-transventricular routes were used in $15 \%$ of the patients. Finally, a transsphenoidal procedure performed via either a standard sublabial microscopic approach $(5.5 \%)$ or an endonasal extended endoscopically assisted approach (17\%) was used in the remainder of cases.

The postoperative outcome was documented in 291 of the 338 patients with $\mathrm{CP}$ who underwent surgery. Overall, $30 \%$ mortality $(n=89)$ was registered in this cohort within the 1st month of the surgical procedure. The hypothalamic injury inflicted by surgical maneuvers was the cause of death in 64 of these cases (72\%). Notably, surgery-related mortality was reduced to only $5 \%$ among the patients treated in the MRI era, between 1990 and 2016 (8 deaths in a total of 167 patients with a follow-up assessment). The rate of satisfactory long-term outcome was higher in the latter subgroup of patients (41\%, MRIera subcohort) than in the global series $(29 \%)$, yet the percentage of poor outcomes remained similar for both groups (13\% in the MRI-era subcohort vs $14 \%$ in the global cohort).

\section{Characterization of CP Adherence Defined by 3 Components}

To develop a comprehensive categorization of $\mathrm{CP}$ adherence patterns, we have assessed and correlated the data provided by 3 complementary sources of information: anatomical studies analyzing tumor relationships in whole brain autopsy specimens $(\mathrm{n}=254)$; intraoperative findings described and/or depicted in surgical reports $(n=298)$ and surgical videos $(n=61)$; and pre- and postoperative MRI 
A

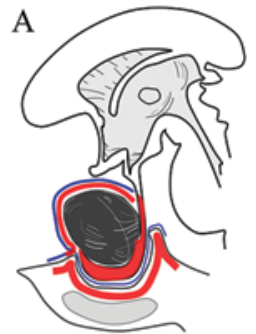

Sella - Gland

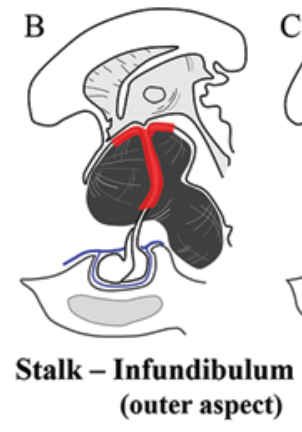

Stalk - Infundibulum (outer aspect)

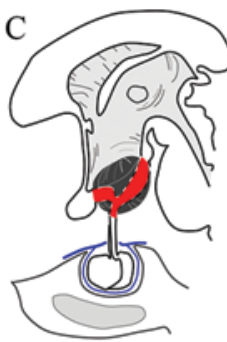

TVF

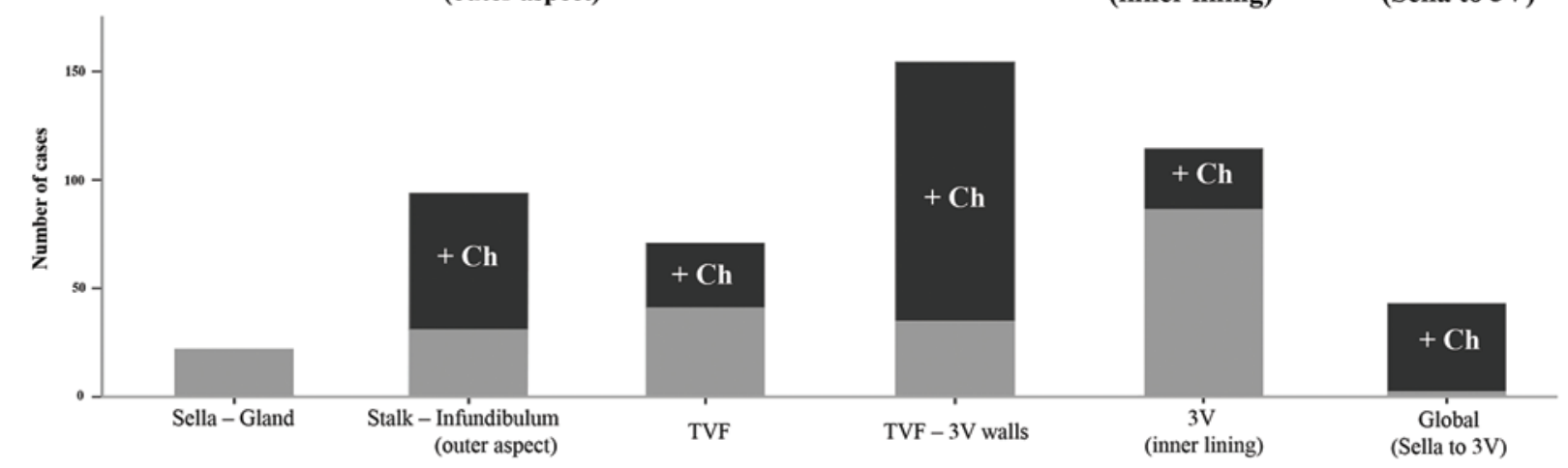

Sella-Gland

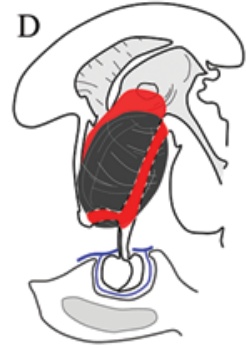

TVF - 3V walls

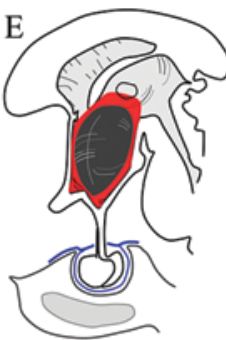

3V

(inner lining)

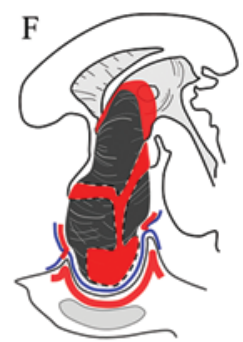

Global

(Sella to 3V)

Structures attached

FIG. 2. Distribution of CPs according to the groups of anatomical structures of the hypophyseal-hypothalamic axis attached to the tumor. Schematic drawings (upper row) and bar chart distribution (lower row) of the 6 groups of structures adhered to the tumor. A: Sella-Gland: tumor attachment occurs within the sella turcica, below the diaphragma sellae, including the junction of the PG with the PS. B: PS-Infundibulum (outer aspect): attachment to the solid portion of the PS and the outer aspect of the infundibulum. C: TVF: attachment to the entire thickness of the TVF. D: TVF-3V walls: attachment to the TVF and 3V walls. E: 3V (inner lining): attachment to the ependymal lining of the 3V cavity. F: Global (Sella to 3V): attachment to all structures of the hypophyseal-hypothalamic axis. The dark gray area within each bar (labeled "+ Ch") represents the proportion of CPs within each category showing adherence to the optic chiasm. Significant differences in the percentage of chiasm adherences were observed among the 6 groups $(p<0.001)$. Note that adhesion to the optic chiasm never occurred in the "Sella-Gland" group, whereas it was found in $95 \%$ of tumors with "Global" attachment.

studies of surgically treated patients $(n=153)$. The types of $\mathrm{CP}$ adherence categorized in this work were defined after integrating the anatomical information regarding the $\mathrm{CP}-$ brain relationships gathered from autopsy studies into the intraoperative and MRI findings of surgical studies. This process allowed the identification of the 3 independent parameters or components of the $\mathrm{CP}$ attachment as detailed below.

\section{First Component of CP Attachment: Anatomical Structures Involved}

The anatomical structure along the hypophyseal-3V vertical axis presenting the maximal adherence to the tumor is specified, for each case, in the Supplemental Table. Most tumors showed the maximal adhesion to the entire thickness of the TVF $(54 \%, \mathrm{n}=268)$. For a proper surgical assessment of the potential risk of hypothalamic injury, an analysis of the groups of hypophyseal-hypothalamic structures attached to the tumor was performed (Fig. 2). A predominant adhesion to the TVF and the lower walls of the $3 \mathrm{~V}$ was observed in $31 \%$ of tumors $(\mathrm{n}=154)$. Approximately $20 \%$ of CPs presented with attachment to the PS and the outer aspect of the infundibulum $(\mathrm{n}=94)$. Finally, in $23 \%$ of cases $(n=114)$ the lesion was adhered only to the inner lining of the $3 \mathrm{~V}$. The presence of a significant $\mathrm{CP}$ attachment to the optic chiasm varied significantly among these groups $(p<0.001)$. No chiasmatic attachment was observed among CPs attached to the sella-PG, whereas it was found in $67 \%$ of tumors that adhered to the outer infundibulum, a rate that increased up to $77 \%$ for lesions that adhered to the TVF-3V.

\section{Second Component of CP Attachment: Morphological Pattern of Adhesion}

The anatomical and surgical evidence for the 6 morphological patterns of CP adherence identified in this cohort is shown in Fig. 3. The most frequently observed morphology was the circumferential attachment, found in $27 \%$ of tumors $(n=134)$. The sessile attachment was present in $21 \%$ of cases. The ring-like pattern, consisting of a band of attachment around the central portion of the tumor, occurred in 19\%. The predominant adhesion around the top portion of the tumor, or cap-like pattern of adherence, was evidenced in $14 \%$ of CPs. The same rate was observed for the inverted type of adhesion, located around the bottom portion of the $\mathrm{CP}$ or in a bowl-like pattern. Finally, only $5.4 \%$ of cases $(n=27)$ showed a pedicle attachment to the inner aspect of the $3 \mathrm{~V}$. 


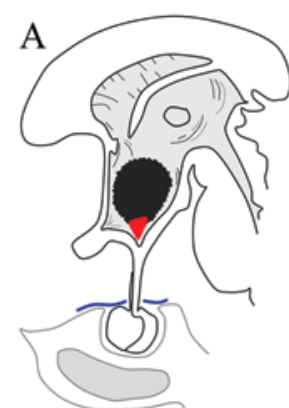

Pedicle
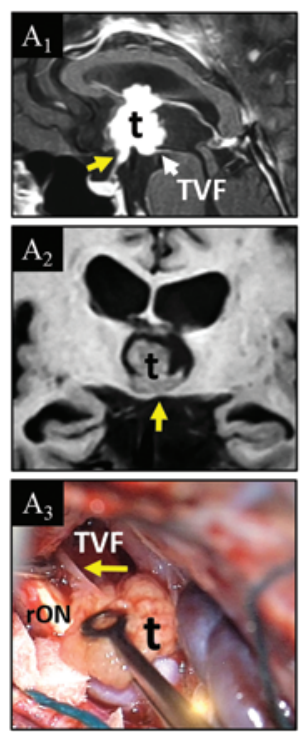

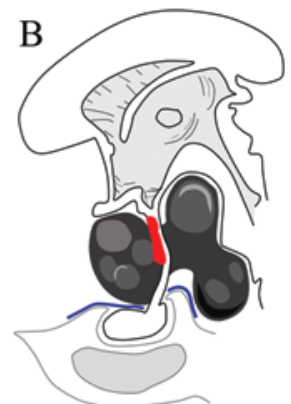

Sessile
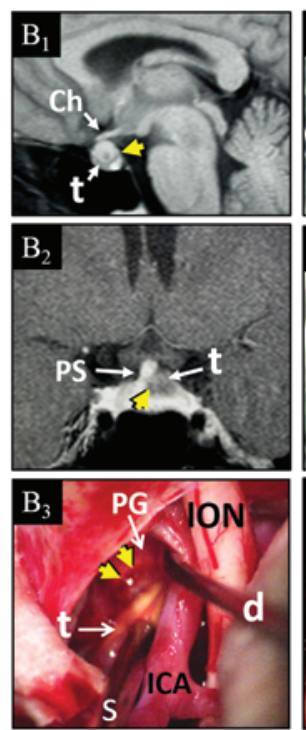

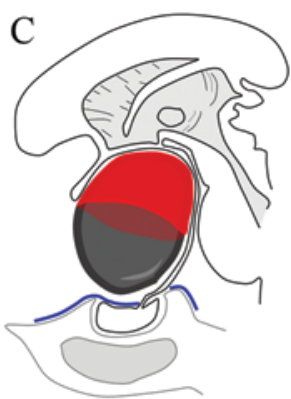

Cap-like
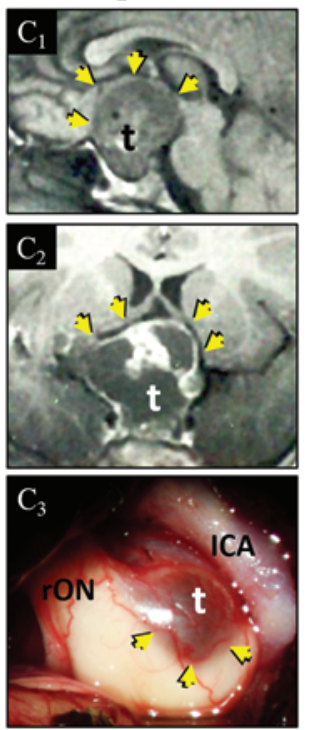

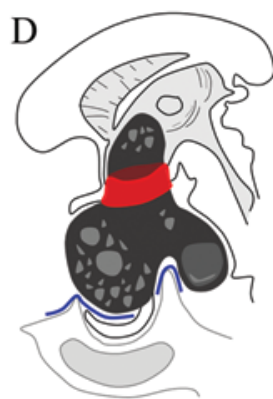

Ring-like
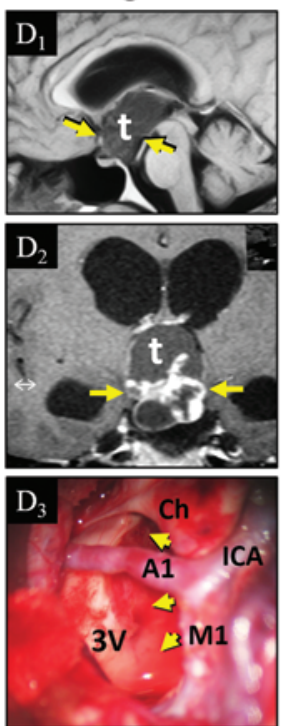

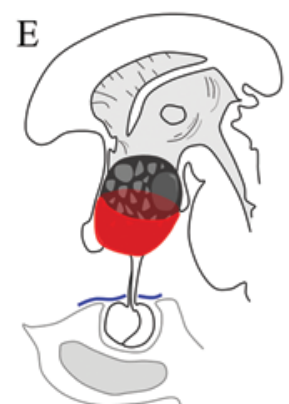

Bowl-like
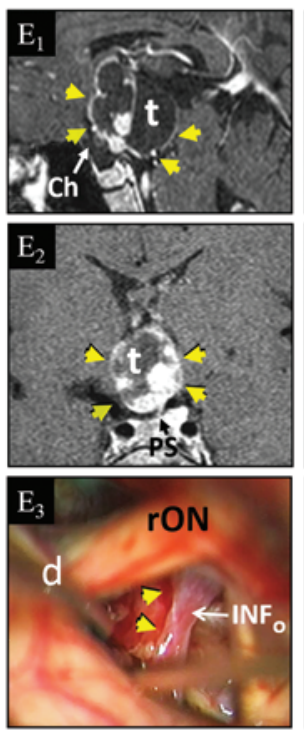

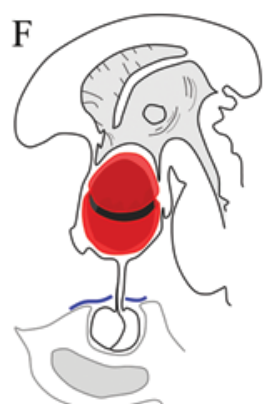

Circumferential
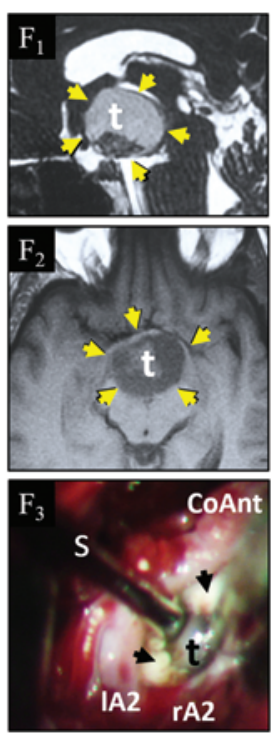

FIG. 3. Morphological patterns of CP adherence: MRI and surgical evidence for the 6 major categories. A: Pedicle or gliovascular stem attachment, found in 27 of 500 cases (5.4\%). A: Midsagittal contrast-enhanced T1-weighted MRI scan showing a strictly intraventricular papillary CP attached by a pedicle (yellow arrow) to the TVF. $\mathbf{A}_{2}$ : Coronal T1-weighted scan of the same tumor. Note the gap between the tumor boundaries and the inner aspects of the $3 \mathrm{~V}$ except at the basal point of attachment (arrow). $\mathbf{A}_{3}$ : Surgical view through a right pterional subchiasmatic and transinfundibular approach showing the pedicle attachment (arrow) of the papillary CP. Note the integrity of the TVF beneath the tumor. rON = right optic nerve. B: Sessile pattern, consisting of a patch area of adhesion (21\% of cases). $\mathbf{B}_{1}$ and $\mathrm{B}_{2}$ : Midsagittal and coronal MRI scans showing a sellar-suprasellar CP with a sessile attachment (yellow arrow) to the PS. $\mathrm{Ch}=$ optic chiasm. $\mathbf{B}_{3}$ : Left pterional view showing petechial bleeding (yellow arrows) at the area of sessile attachment of the tumor to the PS-PG junction. The left internal carotid artery (ICA) is being lifted with a dissector (d) to show the junction area between the PG and the PS. The sucker is placed over the tumor's yellow capsule. ION = left optic nerve. C: Cap-like pattern, characterized by a large extent of adhesion at the upper half of the tumor (14\% of cases). $\mathrm{C}_{1}$ and $\mathrm{C}_{2}$ : Midsagittal and coronal MRI scans showing a suprasellar-pseudointraventricular $\mathrm{CP}$ attached to the upwardly displaced TVF (arrows). C $C_{3}$ : Right pterional view showing a CP whose upper pole is attached to the upwardly displaced TVF and stretched chiasm (arrows). D: The ring-like attachment is characterized by a circular band of brain tissue, usually the remnants of the TVF, adhering to the center band of the tumor surface (19\% of cases). $\mathbf{D}_{1}$ and $\mathbf{D}_{2}$ : Midsagittal and coronal MRI scans showing an infundibulo-tuberal CP with ring-like attachment (arrows). $\mathbf{D}_{3}$ : Translamina terminalis view after radical resection of the tumor showing the ring-shaped bleeding (arrows) as residual mark of the attachment between the CP and the borders of the breached TVF. A1 = segment of the anterior cerebral artery; M1 = segment of the middle cerebral artery. E: Bowl-like pattern (13.5\% of cases in our cohort). $E_{1}$ and $E_{2}$ : Midsagittal and coronal MRI scans showing an infundibulo-tuberal CP whose lower half portion is attached to the TVF and walls (arrows). $\mathbf{E}_{3}$ : Intraoperative view through a right pterional subchiasmatic approach after CP removal shows petechial bleeding at the lower region of the $3 \mathrm{~V}$ cavity (arrows) where the tumor was attached. The right optic chiasm is being pushed medially with a dissector to show the inner aspect of the infundibulum. Note the intactness of the outer aspect of the infundibulum $\left(\mathrm{INF}_{0}\right)$. F: Circumferential pattern of adherence, in which the whole CP surface presents with adhesions to the surrounding tissue ( $27 \%$ of cases). $\mathrm{F}_{1}$ : Midsagittal heavily T2-weighted MRI scan showing a cystic infundibulo-tuberal CP entirely wrapped in a layer of nervous tissue, which corresponds to the stretched remnant of the TVF (arrows). $F_{2}$ : Axial T1-weighted scan of the same tumor with circumferential attachment (arrows). $\mathbf{F}_{3}$ : Intraoperative view through an anterior interhemispheric approach between the left and right A2 segments of the anterior cerebral artery (IA2, rA2) showing the gliotic nervous tissue that surrounds the whole tumor (arrows). The sucker (s) is placed over the bluish CP capsule. CoAnt = communicating anterior artery; $t=$ tumor. 


\section{Third Component of CP Attachment: Adhesion Strength}

Figure 4 shows the anatomical, histological, neuroradiological, and surgical evidence for the 4 degrees of adhesion strength observed in this cohort. Loose or dissectible attachments allowing a practically effortless separation of the CP were observed in only $8 \%$ of the cases $(n=41)$. A tight union requiring sharp dissection to separate the $\mathrm{CP}$ was found in $32 \%$ of the cases $(n=159)$. A true fusion between the outer border of the tumor and the adjacent tissue was observed in $40 \%$ of the cases $(n=198)$. Last, the tumor had replaced the TVF in $20 \%$ of the cases $(n=100)$.

\section{Major CP Adherence Types}

Some characteristic combinations of the 3 components of $\mathrm{CP}$ attachment give rise to the appearance of the major adherence types observed in this cohort. Specific morphological patterns of adherence and degrees of adhesion strength were repeatedly observed to occur together when the $\mathrm{CP}$ attachment involved particular anatomical structures $(p<0.001)$. For example, the pedicle pattern involved $\mathrm{CP}$ attachments to the inner aspect of the TVF in more than $90 \%$ of cases. In contrast, $41 \%$ of CPs involving the entire TVF thickness and 50\% of the tumors involving both the TVF and the $3 \mathrm{~V}$ walls had a circumferential attachment. In two-thirds of the latter pattern the tumor was fused both to the TVF remnants and to the $3 \mathrm{~V}$ walls surrounding it. More than $80 \%$ of CPs with a global adherence to the hypophyseal-hypothalamic axis showed a ring-like pattern of attachment between the lesion and the TVF. In 70\% of these cases the tumor had replaced the infundibulo-tuberal area. The sessile adherence pattern generally occurred in CPs attached to the inner lining of the $3 \mathrm{~V}(46 \%)$ or to the sellar area $(41 \%)$. Sixty percent of sessile attachments had a tight degree of adhesion. Finally, the tumors attached to the PS and the pial aspect of the infundibulum most commonly showed the cap-like attachment (52\%), which was tight in $44 \%$ of the cases and loose in $24 \%$.

\section{Relationships Between CP Topography and Tumor Adherence}

We found a strongly significant relationship between the topography of the tumor and its adherence pattern ( $\mathrm{p}$ $<0.001$ ) (Fig. 5A and B). Approximately $60 \%$ of suprasellar CPs folding the TVF upward (pseudointraventricular topography) had a cap-like attachment to the outer aspect of the infundibulum. In contrast, all tumors with a tight pedicle attachment corresponded to the strictly intraventricular topography. The sessile type of attachment to the sella-PG occurred in half of sellar-suprasellar CPs. A sessile attachment to the ependymal lining of the $3 \mathrm{~V}$ was also present in $46 \%$ of strictly intraventricular tumors.

The CPs considered not strictly intraventricular or infundibulo-tuberal that developed within the neural tissue of the TVF frequently presented a circumferential pattern of adherence (56\%). In two-thirds of infundibulo-tuberal $\mathrm{CPs}$ the tumor capsule was fused to the surrounding brain tissue; most of the time to the hypothalamus. Last, almost $90 \%$ of sellar-suprasellar CPs invading the 3V (secondary $3 \mathrm{~V}$ CPs) showed a ring-like pattern of adhesion to the TVF, usually with replacement of the latter structure.

\section{Pathological Features of CPs Predicting the Type of Attachment}

Table 1 shows the most important significant relationships between the tumor's gross pathological features and the 3 components that define its attachment. Giant CPs $\geq$ $5 \mathrm{~cm}$ in diameter presented the widest and strongest attachments to the entire hypophyseal-hypothalamic axis ( $\mathrm{p}$ $<0.001$ ). A ring-like adherence pattern was observed in almost $40 \%$ of tumors larger than $\geq 5 \mathrm{~cm}$, whereas sessile attachments predominated among small CPs (37\%). Increasing degrees of adhesion strength were evidenced as the tumor increased in size (Fig. 5C and D). Whereas $45 \%$ of small CPs showed a tight attachment, $43 \%$ of medium to large-sized tumors were fused to surrounding structures, and $38 \%$ of giant CPs had replaced the anatomical structures involved in the attachment.

Tumor shape and consistency were also found to be significantly associated with the morphology and strength of adhesion. The loosest attachments were associated with the pear-shaped type of CP developed from the sella turcica $(p<0.001)$. Among multilobulated CPs, the ring-like pattern of attachment occurred in $45 \%$ of cases, most of them with replacement of the TVF. The capsule of elliptical CPs involving the $3 \mathrm{~V}$ was fused to the $3 \mathrm{~V}$ walls in half of cases. Concerning tumor consistency, more than $50 \%$ of solid CPs presented a sessile or pedicle attachment, whereas tumors with a mixed consistency more commonly showed a ring-like pattern (57\%) and upper cystic-basal solid lesions a circumferential type of attachment (59\%). Strictly intraventricular cystic CPs with a basal cauliflower nodule presented either a sessile $(46 \%)$ or a circumferential $(42 \%)$ adherence pattern to the $3 \mathrm{~V}$ walls.

\section{Histological Features of CPs Related to Tumor Adherence}

Tumor histology was significantly associated with CP adherence (Table 1). The adamantinomatous variant was associated with the widest (ring-like/circumferential, in 54\%) and strongest (fusion/replacement, in $73 \%$ ) types of adherence, whereas the squamous-papillary variant presented predominantly a sessile or pedicle attachment (63\%). CP invasion of the adjacent brain tissue, verified with histological or MRI studies, was a feature significantly associated with the replacement of brain tissue by the tumor, as seen with the ring-like pattern replacing the TVF, the macroscopic correlate of brain invasion ( $\mathrm{p}$ $<0.001$ ). Brain invasion was also rather frequent in the circumferential pattern of adhesion (65\%) and among CPs fused to adjacent brain tissue (70\%), but it was only observed in $10 \%$ of sessile adhesions. A layer of peritumoral reactive gliosis at the $\mathrm{CP}$-brain interface was present in $86 \%$ of ring-like attachments and in $80 \%$ of circumferential adhesions with a CP-brain tissue fusion $(\mathrm{p}<0.001)$. Finally, calcifications were observed in CPs with the strongest adhesions, in $75 \%$ of fused attachments and $88 \%$ of brain tissue replacements, whereas loose adhesions were typically observed in noncalcified CPs $(\mathrm{p}<0.001)$.

\section{Epidemiological, Clinical, and MRI Features Related to CP Attachment}

Table 2 shows the major relationships between the 3 

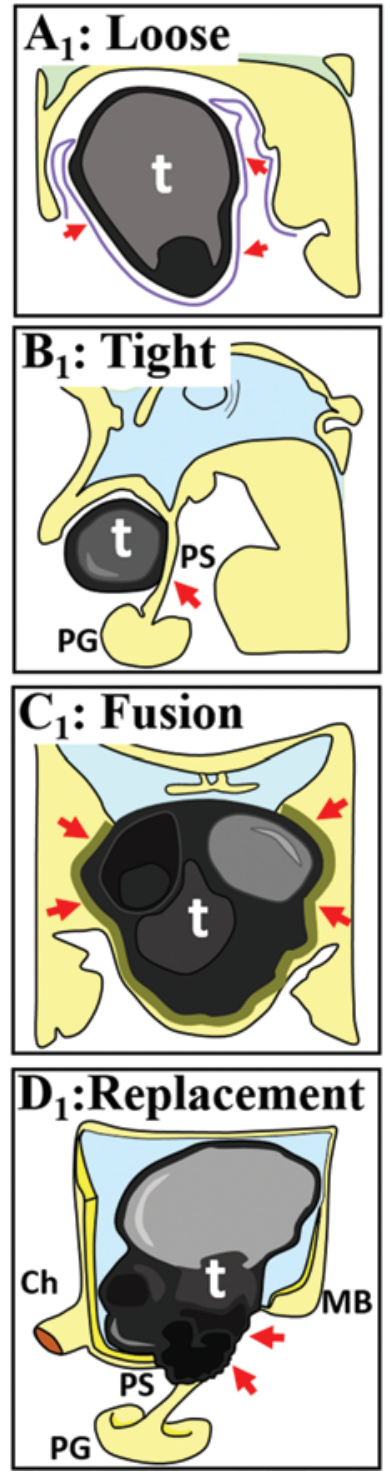
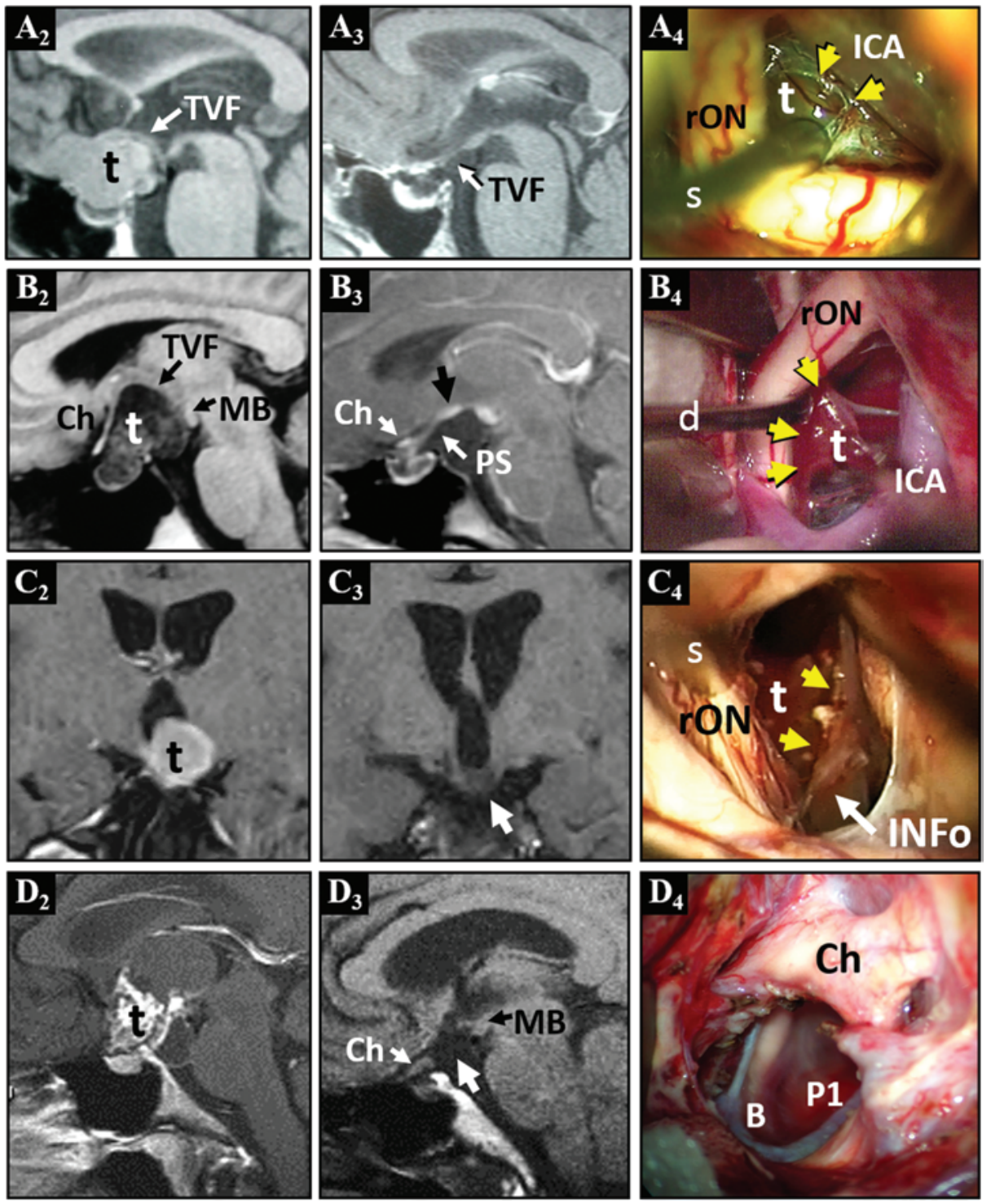

FIG. 4. Adhesion strength of CPs: MRI and surgical evidence characterizing the 4 major degrees of adhesion. $\mathbf{A}_{1}-\mathbf{A}_{4}$ : Loosedissectible adhesion (8\% of cases). $\mathbf{A}_{1}$ : Schematic sagittal drawing showing the loose cleavage plane between the tumor and the contiguous nervous tissue. Note the arachnoid layer between the tumor capsule and the normal brain tissue (arrows). $\mathbf{A}_{2}$ : Preoperative midsagittal MRI scan showing a sellar-suprasellar CP pushing the TVF upward. $\mathrm{A}_{3}$ : Postoperative scan showing the intactness of the TVF following the easy division of the loose CP attachment. $\mathbf{A}_{4}$ : Right pterional view showing the arachnoid layer (arrows) between the tumor capsule and the surrounding neurovascular structures. ICA = internal carotid artery; rON = right optic nerve; $\mathrm{s}=$ sucker. $\mathbf{B}_{1}-\mathrm{B}_{4}$ : Tight adhesion ( $32 \%$ of cases). $\mathbf{B}_{1}$ : Schematic sagittal drawing of a suprasellar CP tightly attached to the upper PS (arrow). $\mathbf{B}_{2}$ : Sagittal preoperative MRI scan showing a sellar-suprasellar pseudointraventricular CP beneath an upwardly displaced TVF and stretched chiasm (Ch). MB = mammillary body. B $_{3}$ : Postoperative contrast-enhanced T1-weighted MRI scan obtained after complete removal showing the integrity of the PS and the recovery of the normal morphology of the optic chiasm. Note the hyperintense signal at the upper PS and the infundibulo-tuberal area, the mark of the tumor's tight attachment (black arrow). $\mathbf{B}_{4}$ : Right pterional approach showing tight attachment (arrows) between the tumor capsule and the junction between the outer aspect of the infundibulum and the upper PS. $d=$ dissector. $\mathbf{C}_{1}-\mathbf{C}_{4}$ : Fusion $\left(40 \%\right.$ of cases). $\mathbf{C}_{1}$ : Schematic coronal drawing showing an infundibulo-tuberal $\mathrm{CP}$ without an identifiable cleavage plane between the tumor and the walls of the $3 \mathrm{~V}$ (arrows). $\mathrm{C}_{2}$ : Coronal preoperative MRI scan showing an infundibulo-tuberal CP fused to the left hypothalamus. $\mathrm{C}_{3}$ : Postoperative scan obtained following radical tumor resection revealing a hypointense signal in the left hypothalamus (arrow). $\mathrm{C}_{4}$ : Intraoperative view through a right pterional subchiasmatic approach showing tumor tissue fused to the inner side of the infundibulum (arrows). The outer side of the infundibulum (INFo) presents a normal appearance. $\mathbf{D}_{1}-\mathbf{D}_{4}$ : Replacement $\left(20 \%\right.$ of cases). $\mathbf{D}_{1}$ : Schematic sagittal drawing showing the replacement of the infundibulo-tuberal area by the solid portion of an intraventricular $C P$. $D_{2}$ : Midsagittal MRI scan showing an infundibulo-tuberal or not strictly intraventricular CP that has replaced the TVF. $\mathrm{D}_{3}$ : Postoperative MRI scan following radical removal the CP demonstrating a breached TVF (arrow) corresponding to the tuber cinereum replaced by the tumor. $\mathbf{D}_{4}$ : Intraoperative view through the lamina terminalis after complete removal of the CP showing the basilar artery (B) and the right posterior cerebral artery (P1) through the breached TVF. 

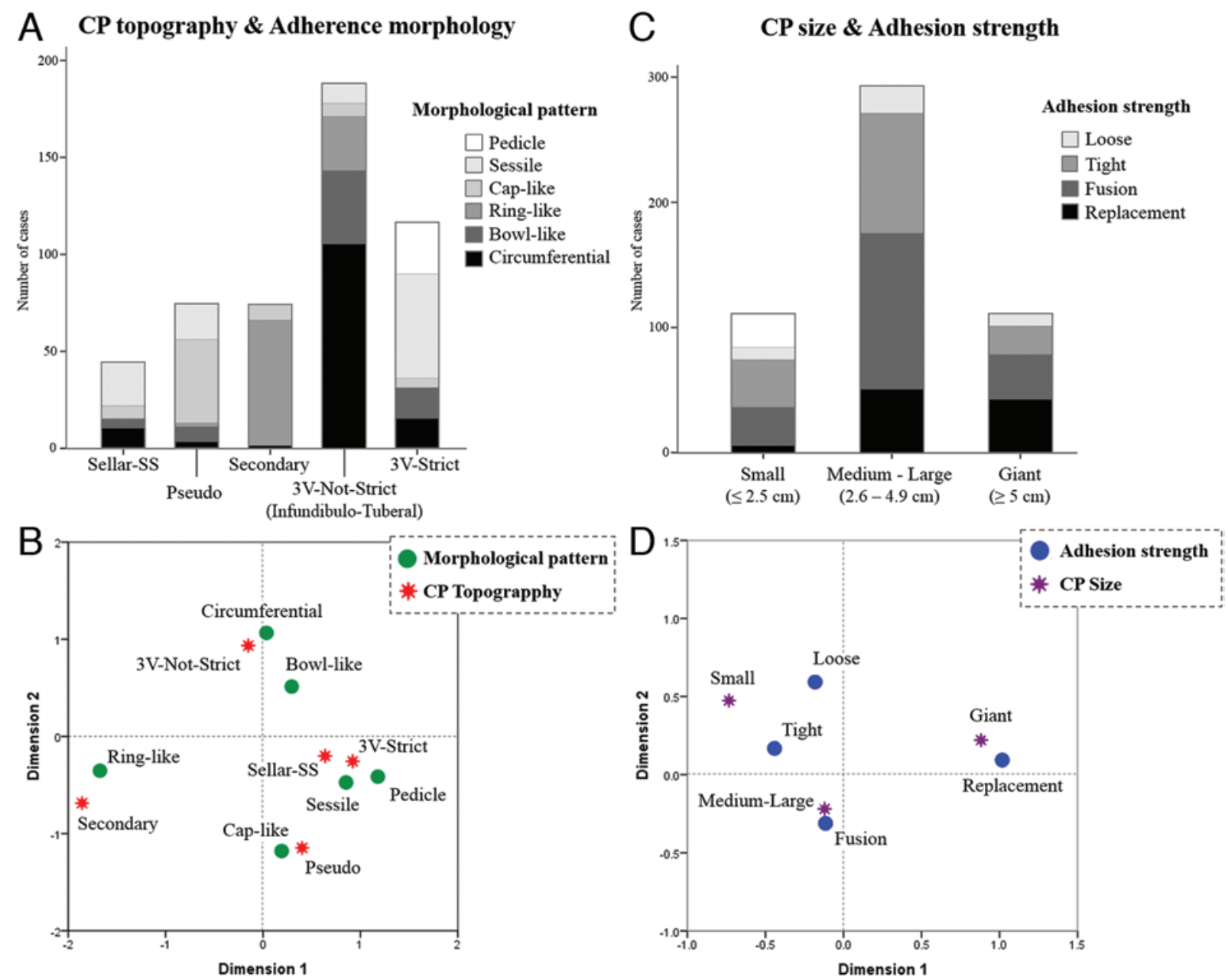

FIG. 5. Relationships between pathological features of CPs and tumor adherence. A and B: Bivariate relationships between the $\mathrm{CP}$ topography and the morphology of CP adhesion. A: Stacked bar chart displays the distribution of the 6 morphological patterns of CP adherence within each topographical category $(p<0.001)$. Half of the tumors with sellar-suprasellar topography (Sellar-SS) had a sessile pattern; $57 \%$ of suprasellar-pseudointraventricular (Pseudo) CPs showed a cap-like adhesion, and $88 \%$ of suprasellar-secondary (Secondary) lesions presented with a ring-like attachment. Among intraventricular CPs, the infundibulo-tuberal topography (3V-Not Strict) either showed a circumferential (56\%) or a bowl-like $(20 \%)$ pattern, whereas the strictly intraventricular category (3V-Strict) was associated with a sessile (46.2\%) or pedicle (23\%) type of attachment. B: A 2D plot of the correspondence analysis between CP topography and morphological patterns of adherence illustrates the most common associations observed. C and D: Bivariate relationships between the CP size and the degree of adhesion strength. C: The stacked bar chart shows the distribution of degrees of adhesion strength within each CP size category $(p<0.001)$. Note that the larger the tumor, the stronger the degree of adhesion. D: A 2D plot of the correspondence analysis between CP size and degrees of adhesion strength illustrates that small tumors were associated with loose and tight degrees of adhesion, medium-large lesions with fusion, and the giant ones with replacement of the anatomical structures.

components that define the tumor attachment and the patients' age, the clinical manifestations, and the preoperative MRI findings. A significant relationship between the patient's age and the type of CP adherence was found in this cohort. Loose CP attachments tended to occur more frequently in children. The extent of $\mathrm{CP}$ fusion with the brain tissue involved in the attachment increased with age. All CPs with a pedicle attachment were found in adult patients $\geq 40$ years $(\mathrm{p}<0.001)$.

The rate of HICP symptoms increased progressively with the strength of adhesion. Visual deficits mostly occurred in patients with CPs that adhered to the outer infun- dibulum and the PS. The infundibulo-tuberal syndrome is associated with the ring-like (65\%) and the circumferential (58\%) patterns of attachment to the TVF. Hypothalamic dysfunction such as behavioral changes, symptoms of autonomic nervous system, and memory defects were commonly observed in patients with intraventricular CPs presenting with either a pedicle $(72 \%)$ or a circumferential $(60 \%)$ attachment to the $3 \mathrm{~V}(\mathrm{p}<0.001)$.

The appearance of the structures of the hypophyseal-hypothalamic axis on the preoperative MRI scans informs practitioners about the pattern and degree of tumor adherence (Table 2). For example, the visualiza- 
TABLE 1. Pathological factors related to CP adherence in a cohort of 500 cases

\begin{tabular}{|c|c|c|c|c|c|c|}
\hline $\begin{array}{l}\text { Tumor Variable } \\
\& \text { Categories }\end{array}$ & $\begin{array}{c}\text { Structures Attached } \\
\text { (hypophyseal-hypothalamic axis) }^{*}\end{array}$ & $\begin{array}{c}p \\
\text { Value }\end{array}$ & Morphological Pattern* & $\begin{array}{c}p \\
\text { Value }\end{array}$ & $\begin{array}{l}\text { Adhesion } \\
\text { Strength* }\end{array}$ & $\begin{array}{c}p \\
\text { Value }\end{array}$ \\
\hline \multicolumn{7}{|l|}{ CP topography } \\
\hline S-SS & Sella-gland & \multirow{5}{*}{$<0.001$} & Sessile & \multirow{5}{*}{$<0.001$} & Tight/loose & \multirow{5}{*}{$<0.001$} \\
\hline SS-pseudo 3V & PS-infund (outer) & & Cap-like & & Loose & \\
\hline SS-secondary 3V & TVF (whole thickness) & & Ring-like & & Replaced & \\
\hline 3V-not strict & TVF-3V & & Circumferential/bowl-like & & Fused & \\
\hline 3V-strict & 3V (inner lining) & & Sessile/pedicle & & Tight & \\
\hline \multicolumn{7}{|l|}{$\mathrm{CP}$ size in $\mathrm{cm}$} \\
\hline Small; $\leq 2.5$ & 3V (inner lining) & \multirow{3}{*}{$<0.001$} & Sessile/pedicle & \multirow{3}{*}{$<0.001$} & Tight/loose & \multirow{3}{*}{$<0.001$} \\
\hline Medium-large; $2.6-4.9$ & TVF-3V & & Circumferential & & Fused & \\
\hline Giant; $\geq 5$ & Global (sella to 3V) & & Ring-like/cap-like & & Replaced & \\
\hline \multicolumn{7}{|l|}{ CP shape } \\
\hline Pear-like & PS-infund (outer)/sella-gland & \multirow{4}{*}{$<0.001$} & Sessile/bowl-like & \multirow{4}{*}{$<0.001$} & Loose & \multirow{4}{*}{$<0.001$} \\
\hline Round & 3V (inner lining)/TVF-3V & & Circumferential/sessile/pedicle & & Tight/fused & \\
\hline Elliptical & TVF-3V & & Ring-like & & Fused & \\
\hline Multilobulated & PS-infund (outer)/global & & Ring-like/cap-like & & Replaced & \\
\hline \multicolumn{7}{|l|}{ CP consistency } \\
\hline Pure cystic & PS-infund (outer) & \multirow{5}{*}{$<0.001$} & Cap-like & \multirow{5}{*}{$<0.001$} & Loose & \multirow{5}{*}{$<0.001$} \\
\hline Pure solid & 3V (inner lining) & & Sessile/pedicle & & Tight & \\
\hline Mixed solid-cystic & TVF-3V/global & & Ring-like/circumferential/bowl-like & & Fused/replaced & \\
\hline Cystic-basal solid & TVF-3V & & Circumferential & & Fused & \\
\hline Cystic cauliflower & 3V (inner lining) & & Sessile/circumferential & & Tight & \\
\hline \multicolumn{7}{|l|}{ CP histology } \\
\hline Adamantinomatous & TVF-3V/PS-infund (outer) & \multirow{2}{*}{$<0.001$} & Ring-like/cap-like/bowl-like & \multirow{2}{*}{$<0.001$} & Fused/replaced & \multirow{2}{*}{$<0.001$} \\
\hline Squamous papillary & 3V (inner lining) & & Sessile/pedicle & & Tight/loose & \\
\hline \multicolumn{7}{|l|}{ Calcifications } \\
\hline Present & PS-infund (outer)/TVF-3V & \multirow{2}{*}{$<0.001$} & Cap-like/ring-like/circumferential & \multirow{2}{*}{$<0.001$} & Fused/replaced & \multirow{2}{*}{$<0.001$} \\
\hline Absent & 3V (inner lining) & & Sessile/pedicle & & Loose/tight & \\
\hline \multicolumn{7}{|l|}{ Reactive gliosis } \\
\hline Present & TVF-3V & $<0.001$ & Circumferential/ring-like & 0.006 & Fused/replaced & $<0.001$ \\
\hline \multicolumn{7}{|l|}{ Brain invasion } \\
\hline Present & TVF-3V/global/TVF (whole thickness) & \multirow{2}{*}{$<0.001$} & Ring-like & \multirow{2}{*}{$<0.001$} & Replaced/fused & \multirow{2}{*}{$<0.001$} \\
\hline Absent & 3V (inner lining)/PS-infund (outer) & & Sessile/pedicle & & Tight/loose & \\
\hline
\end{tabular}

Infund (outer) $=$ outer or pial aspect of the infundibulum; S-SS = sellar-suprasellar; SS-pseudo 3V = suprasellar pseudointraventricular; SS-secondary 3V = suprasellar-secondary intraventricular; $3 \mathrm{~V}$-not strict = not strictly intraventricular or infundibulo-tuberal; $3 \mathrm{~V}$-strict = strictly intraventricular.

The classification of structures attached, morphological patterns of adherence, and degrees of adhesion strength are shown in Figs. 2, 3, and 4, respectively.

* Entries show the specific structures attached, morphological patterns, and degrees of adhesion strength that were found to be associated with each category of the tumor variables. When more than one structure, morphological pattern, or adhesion strength are listed, the one showing the strongest association is listed first.

tion of a flattened PG pushed against the sellar floor by a suprasellar CP is a finding associated with the cap-like pattern of adhesion $(\mathrm{p}=0.003)$. An upwardly displaced but intact TVF capping the tumor capsule can be identified on preoperative MRI scans in approximately half of tumors with this type of attachment. In contrast, the infundibulo-tuberal region cannot be visualized in $95 \%$ of CPs with a ring-like type of attachment to the TVF. An anatomically defective or breached TVF will be found after removing the lesion in $75 \%$ of the latter cases $(p<0.001)$. The PS could never be visualized when the $\mathrm{CP}$ presented a ring-like pattern of adhesion to the TVF; however, its lower portion was visible under the tumor in approximately half of infundibulo-tuberal CPs with either a bowl-like or a circumferential attachment to the TVF-3V. We use the term "amputated PS" to describe the latter appearance.

\section{Adherence of CPs: A Factor Related to Surgical Outcome-An Analysis of the MRI-Era Subcohort}

Figure 6 shows the significant relationships between each of the 3 components of CP adherence and the surgical outcome, for both the whole cohort of surgical cases (Fig. 6, upper row [panels A-C]) and the subgroup of pa- 
TABLE 2. Clinical and radiological variables related to CP adherence in a cohort of 500 cases

\begin{tabular}{|c|c|c|c|c|c|c|}
\hline $\begin{array}{l}\text { Variable \& } \\
\text { Categories }\end{array}$ & $\begin{array}{c}\text { Structures Attached } \\
\text { (hypophyseal-hypothalamic axis) }^{*}\end{array}$ & $\begin{array}{c}\mathrm{p} \\
\text { Value }\end{array}$ & $\begin{array}{l}\text { Morphological } \\
\text { Pattern }^{*}\end{array}$ & $\begin{array}{c}\mathrm{p} \\
\text { Value }\end{array}$ & $\begin{array}{l}\text { Adhesion Strength to } \\
\text { the Hypothalamus* }\end{array}$ & $\begin{array}{c}\mathrm{p} \\
\text { Value }\end{array}$ \\
\hline \multicolumn{7}{|l|}{ Age in yrs } \\
\hline $0-19$ & $\begin{array}{l}\leq 9 \text { yrs: PS-infund (outer); 10-19 } \\
\text { yrs: TVF-3V }\end{array}$ & \multirow{3}{*}{$<0.001$} & Cap-like/ring-like & \multirow{3}{*}{$<0.001$} & Replaced/loose & \multirow{3}{*}{$<0.001$} \\
\hline $20-39$ & TVF-3V/3V (inner lining) & & Circumferential/sessile & & Fused & \\
\hline$\geq 40$ & 3V (inner lining) & & Circumferential/sessile/pedicle & & Tight & \\
\hline \multicolumn{7}{|l|}{ Clinical syndrome } \\
\hline $\mathrm{HICP}$ & Global (sella to 3V)/3V/TVF-3V & $<0.001$ & All types but bowl-like & $<0.001$ & If absent: loose & 0.006 \\
\hline Pituitary & Sella-gland/global & $<0.001$ & If absent: pedicle/sessile & 0.001 & Replaced/none & 0.015 \\
\hline Chiasmal & PS-infund (outer) & $<0.001$ & All types but pedicle & 0.085 & NA & NS \\
\hline Infundibulo-tuberal & Global/TVF-3V & $<0.001$ & Ring-like/circumferential & 0.001 & Replaced & $<0.001$ \\
\hline Hypothalamic & 3V (inner lining)/TVF-3V & $<0.001$ & Pedicle/circumferential & $<0.001$ & All degrees but none/loose & $<0.001$ \\
\hline \multicolumn{7}{|l|}{ Preop MRI findings } \\
\hline PG distorted & PS-infund (outer) & \multirow{2}{*}{$<0.001$} & Ring-like/cap-like & \multirow{2}{*}{0.003} & Fused & \multirow{2}{*}{$<0.001$} \\
\hline PG not visible & Sella-gland & & Cap-like & & None/loose & \\
\hline PS amputated & TVF-3V/TVF (whole thickness) & \multirow{2}{*}{$<0.001$} & Circumferential/bowl-like & \multirow{2}{*}{$<0.001$} & Replaced/fused & \multirow{2}{*}{$<0.001$} \\
\hline PS not visible & PS-infund (outer)/global & & Cap-like/ring-like & & Loose & \\
\hline Chiasm distorted & TVF-3V/TVF (whole thickness) & \multirow{2}{*}{$<0.001$} & Bowl-like/sessile & \multirow{2}{*}{0.007} & NA & \multirow{2}{*}{ NS } \\
\hline Chiasm not visible & Global/PS-infund (outer) & & Ring-like & & NA & \\
\hline TVF distorted & PS-infund (outer) & \multirow{2}{*}{$<0.001$} & Cap-like/sessile & \multirow{2}{*}{$<0.001$} & Loose/tight & \multirow{2}{*}{$<0.001$} \\
\hline TVF not visible & TVF-3V/TVF (whole thickness) & & Ring-like/bowl-like & & Replaced/fused & \\
\hline $3 \mathrm{~V}$ wall encroached & TVF-3V/global & 0.003 & If absent: pedicle/sessile & 0.014 & Replaced & 0.003 \\
\hline
\end{tabular}

NA = not applicable; NS = not significant.

The classification of structures attached, morphological patterns of adherence, and degrees of adhesion strength are shown in Figs. 2, 3, and 4, respectively.

* Entries show the specific structures attached, morphological patterns, and degrees of adhesion strength that were found to be associated with each category of the variables analyzed.

tients who underwent operation in the period 1990-2016, known as the MRI era subcohort (Fig. 6, lower row [panels D-F]) $(\mathrm{p}<0.001)$. Notably, the surgical outcome in the MRI subcohort improved markedly over that observed in the global series, with only a $5 \%$ perioperative mortality rate in the former versus a $30 \%$ in the latter, which includes lesions that were surgically treated in the premicrosurgical, precorticoid era. The best outcome was observed for CPs exclusively attached to the sella turcica and the junction of the PG with the PS, a group of lesions with no postoperative mortality (Fig. 6A and D). In contrast, the highest rate of postoperative deaths occurred in lesions attached to the TVF and $3 \mathrm{~V}$ walls $(44.5 \%$ in the global series and $11.5 \%$ in the MRI-era subcohort). The pedicle and the sessile types of adhesion were associated with the best postoperative outcomes. The $\mathrm{CP}$ adhesion pattern associated with the worst outcome was the circumferential to the TVF, with $45 \%$ of deaths in the global series and $14 \%$ in the MRI-era subcohort (Fig. 6B and E). Last, increasing degrees of adhesion strength showed a perfect linear correlation with decreasingly good postoperative outcomes in both cohorts. Moreover, in spite of the mortality reduction in the MRI era, the greater the degree of adhesion the larger the poor outcome rates in both cohorts (Fig. 6C and F).

\section{Estimation of Surgical Risk in CPs: A Novel Risk Stratification Model for CP Surgery Based on Adherence Severity Levels}

We created the variable "adherence severity" with the aim of integrating information from the 3 components of the $\mathrm{CP}$ attachment (structures involved, morphology, and strength of adhesion) and thus separating CPs into similar risk groups. The tumors were grouped into 5 levels of increasing adherence severity: mild (Level I), moderate (Level II), serious (Level III), severe (Level IV), and critical (Level V). Each of these levels included CP cases characterized by a specific set of attachment components, which were chosen according to the similar surgical outcomes shown between the attachment components and the postoperative outcome in the bivariate analyses. In Table 3 the sets of categories for the 3 attachment components defining each level of adherence severity are described. A significant linear relationship was found between increasing levels of adherence severity and increasingly poor outcomes. The death rate was zero for CPs grouped in the level of mild or minimum adherence and increased progressively up to $50 \%$ among the tumors included in the category of maximum or critical severity. These results supported the adequacy of the severity adherence levels categorized in our model. 


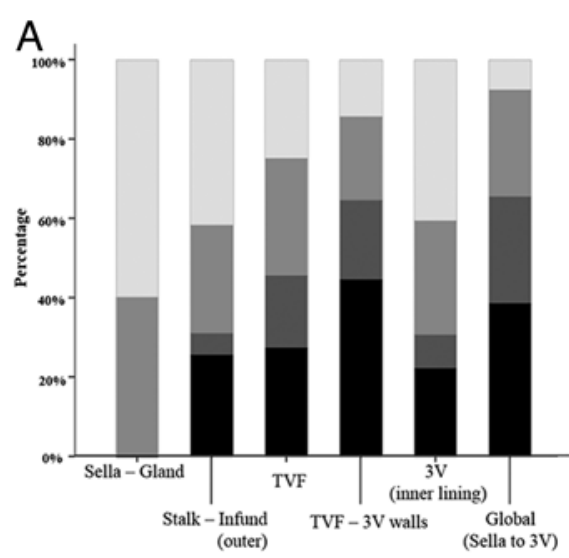

Structures attached

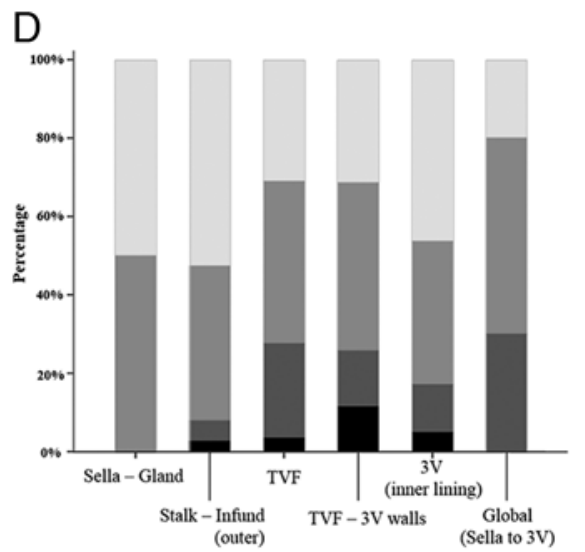

Structures attached

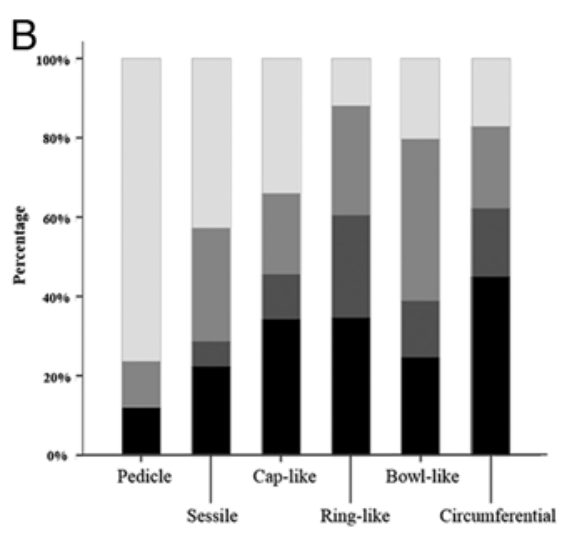

Morphological pattern

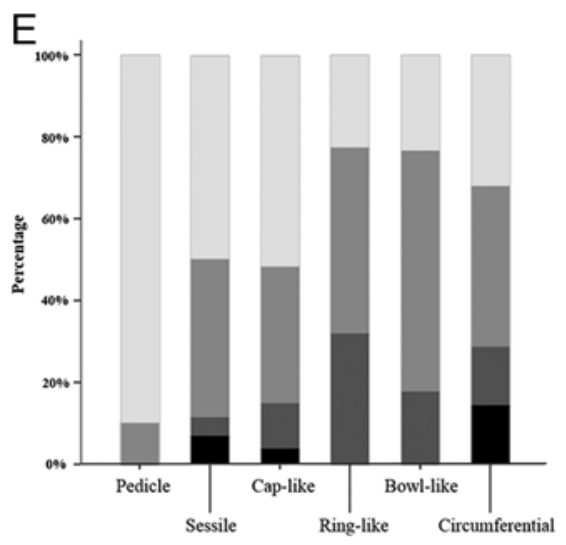

Morphological pattern

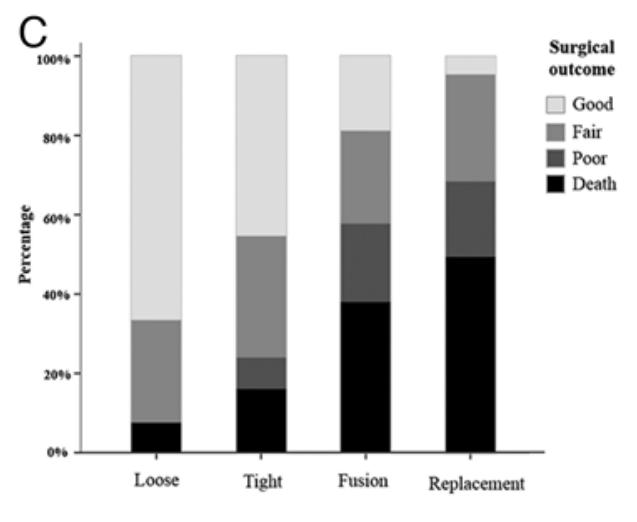

Adhesion strength

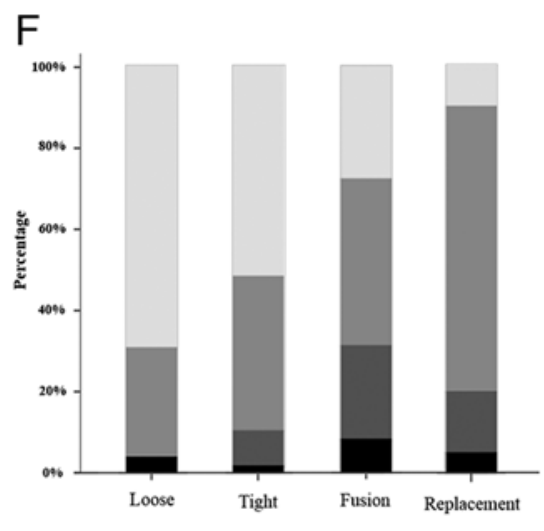

Adhesion strength

FIG. 6. Relationships between the 3 components of CP adherence and surgical outcome. Upper row: Results from the whole cohort (1857-2016). A: Stacked bar graph showing the correlation between the structures attached to the tumor and surgical outcome $(p<0.001)$. Note that the rate of good outcome was as high as $60 \%$ in the group "Sella-Gland" and approximately $40 \%$ in the groups attached to either the outer aspect of the infundibulum ("Stalk-Infund [outer]") or to the inner lining of the 3V. In contrast, two-thirds of CPs attached to the TVF and 3V walls or to the entire length of the hypophyseal-3V axis ("Global") had a poor outcome or died after surgery. B: Stacked bar graph showing the correlation between the morphological pattern of CP adherence and surgical outcome $(p<0.001)$. The best postoperative outcome was reported for CPs with either a pedicle $(76.5 \%)$ or a sessile (43\%) attachment. Perioperative death or poor outcome occurred in $60 \%$ of CPs with a ring-like or a circumferential adherence pattern. C: Stacked bar graph showing the correlation between adhesion strength and surgical outcome $(p<0.001)$. The stronger the degree of adhesion, the worse the outcome. Good outcomes were observed in $67 \%$ and $45.5 \%$ of CPs with loose and tight adherence, respectively. In contrast, postoperative death occurred in half of the tumors that had replaced the TVF. Lower row: Results from the MRI-era subcohort (1990-2016). Stacked bar graphs showing the correlation between surgical outcome and the structures attached to the tumor (D), morphological patterns of CP adherence $(E)$, and degrees of adhesion strength $(F)$. Comparison between the upper and lower graphs shows an analogous distribution of good outcome for all categories of the different adherence components. Poor outcome rates also followed a similar distribution.

A stepwise multivariate hierarchical analysis using the CHAID method was conducted to explore the optimal combination of epidemiological, clinical, and pathological variables providing the best discrimination model for these 5 levels of adherence severity. The CP topography was identified as the variable showing the strongest interaction with the level of adherence severity (Fig. 7A). In subsequent steps the presence of some specific clinical syndromes (HICP, the infundibulo-tuberal syndrome, and/ or hypothalamic dysfunction) and the tumor consistency were selected by CHAID as the independent variables to build a model for prediction of $\mathrm{CP}$ adherence severity. The predictive power of this model was $87 \%$; that is, only by ascertaining preoperatively the tumor topography, its consistency, and the patient's clinical symptoms can a correct preoperative classification of the adherence severity level be achieved in $87 \%$ of cases (Table 4 ).

Finally, a simple correspondence analysis showed that tumor topography by itself explained the level of adherence severity in $73 \%$ of cases. Multivariate analyses in the MRI-era subcohort also identified CP topography as the major predictor of adherence severity. The variance of adherence severity explained only by CP topography increased to $82 \%$ in this subcohort. Five major topographyadherence severity relationships were identified (Fig. 7B, Table 5): 1) the sellar-suprasellar topography was associ- 
TABLE 3. Levels of adherence severity: definition and relationships with surgical outcome and perioperative death due to hypothalamic injury

\begin{tabular}{|c|c|c|c|c|c|c|c|c|}
\hline \multirow[b]{2}{*}{ Level } & \multirow{2}{*}{$\begin{array}{c}\text { No. } \\
\text { of } \\
\text { Cases }\end{array}$} & \multirow[b]{2}{*}{$\begin{array}{l}\text { Structures } \\
\text { Attached }\end{array}$} & \multirow[b]{2}{*}{$\begin{array}{l}\text { Morphological } \\
\text { Pattern }\end{array}$} & \multirow{2}{*}{$\begin{array}{l}\text { Strength } \\
\text { of } \\
\text { Adhesion }\end{array}$} & \multicolumn{3}{|c|}{ Surgical Outcome (\%)* } & \multirow{2}{*}{$\begin{array}{l}\text { Periop Death due } \\
\text { to Hypothalamic } \\
\text { Injury }(\%)\end{array}$} \\
\hline & & & & & $\begin{array}{l}\text { Good } \\
\text { \& Fair }\end{array}$ & Poor & Death & \\
\hline I-mild & 18 & Sella-gland & Sessile/circumferential & Loose/tight & 100 & 0 & 0 & 0 \\
\hline II-moderate & 70 & 3V (inner lining) & Pedicle/sessile & Loose/tight & 77.5 & 2.5 & 20 & 50 \\
\hline III-serious & 81 & PS-infund (outer) & Sessile/cap-like & Loose/tight/fusion & 68.7 & 6.3 & 25 & 92 \\
\hline IV-severe & 229 & TVF/TVF-3V/3V & Bowl-like/ring-like/circumferential & Tight/fusion/replacement & 41.4 & 21.1 & 37.5 & 69 \\
\hline V-critical & 30 & Global (sella to 3V) & Ring-like & Replacement & 21.4 & 28.6 & 50 & 100 \\
\hline Total & 428 & & & & $n=132$ & $\mathrm{n}=35$ & $\mathrm{n}=75$ & $n=55$ \\
\hline
\end{tabular}

Adherence severity was defined according to the structures attached to the tumor, the morphological pattern of tumor adherence, and the degree of adhesion strength. A total of 428 tumors from the cohort of $500 \mathrm{CPs}$ were included in multivariate analysis. The categorization of structures attached, morphological patterns, and degrees of adhesion strength are explained in Figs. 2, 3, and 4, respectively.

* Surgical outcome was known in 242 of the 428 cases. A significant relationship was found between adherence severity and both the surgical outcome ( $p<0.001)$ and the death rate caused by hypothalamic injury $(p=0.049)$. Note that the rate of good/fair outcomes progressively decreased from the mild to the critical levels of $C P$ adherence severity, whereas the opposite occurred for the rates of poor outcome and perioperative death. Hypothalamic dysfunction was the cause of death in 55 of 75 patients who died within the 1st month following surgery. The last column of the table presents the percentage of patients whose death was due to surgical hypothalamic injury for each level of adherence severity. Note that all deaths that occurred in the critical level were secondary to hypothalamic dysfunction following surgery. In contrast, only half of the perioperative deaths occurring in the moderate level were due to hypothalamic injury -a finding related to both the reduced extent and the low strength of the adhesion compared to that present in the remaining CPs involving the $3 \mathrm{~V}$.

ated with the mild and serious levels of adherence severity; 2) the strictly intraventricular topography was associated with the moderate level of severity; 3) the suprasellarpseudointraventricular topography was associated with the serious one; 4) the infundibulo-tuberal was associated with the severe level; and 5) the secondary intraventricular was associated with the critical level of adherence severity. Consequently, an accurate MRI diagnosis of CP topography represents the fundamental information that should be known preoperatively to roughly estimate the severity of $\mathrm{CP}$ adherence that must be tackled.

\section{Discussion}

\section{Adherence of CPs: Toward a Precise Pathological Characterization}

Adherence of CPs is a familiar but poorly understood subject to neurosurgeons. With a few exceptions, a proper account of $\mathrm{CP}$ adherence is lacking in most surgical series. This critical factor requires an exhaustive analysis and a sound categorization, because in many cases it guides the surgeon's decision on the radicality of tumor excision. Regrettably, when a description of CP adherence is provided, it is usually too imprecise or exclusively derived from the surgeons' subjective impressions. The words adherence, adhesiveness, attachment, brain invasion, infiltration, encroachment, and destruction have been used interchangeably by different authors to refer to the gross sticking of CPs to neighboring neurovascular structures. Nevertheless, these terms are far from being identical and need a precise clarification of their meanings. The term "CP adherence" denotes a subjective quality, derived from the surgeon's intuitive perception of the joining forces that oppose the dissection maneuvers used to release the tumor from the surrounding structures. By contrast, the term " $\mathrm{CP}$ attachment" refers to the objective, specific pathological features of the adhesion, defined by its position, morphology, and extent. The original or "primary" CP attachment occurs at the initial site of tumor development. "Secondary" CP attachments usually occur at later stages of tumor development, due to the dynamic interactions between the tumor and the contiguous structures.

In this work we present a comprehensive characterization of the major CP adherence types, based on the precise analysis of the 3 essential components that define the attachment: 1) the location and 2) the morphology or extent of attachment (two objective parameters evidenced by autopsy and surgical studies); and 3) the degree of adhesion strength (one subjective aspect described in surgical reports or observed in surgical videos). The $\mathrm{CP}$ adherence types were initially defined on the basis of the insight gained from the examination of the anatomical sections in the autopsy studies included in our cohort. These autopsy studies represent the most complete and objective source of evidence regarding $\mathrm{CP}$ adherence. Anatomical evidence was then correlated with the findings from surgical and MRI studies. The goal of this categorization scheme of $\mathrm{CP}$ adherence is to forecast the potential risks associated with a radical resection of the lesion.

This historical cohort of 500 well-described CPs (see Supplemental Table) has several advantages, but is also subject to some limitations. Our results might be considered flawed due to the retrospective and potentially nonrepresentative selection of cases for the cohort, which covers the historical period prior to the introduction of major diagnostic and therapeutic advances in CP surgery. In addition, a number of the individual tumors may have been reported because of their odd or unusual pathological features, the presence of unusual clinical manifestations, or the occurrence of unforeseen complications. Nevertheless, the consistency of our results is supported by two facts: first, most of the oldest cases in our cohort, reported be- 
A

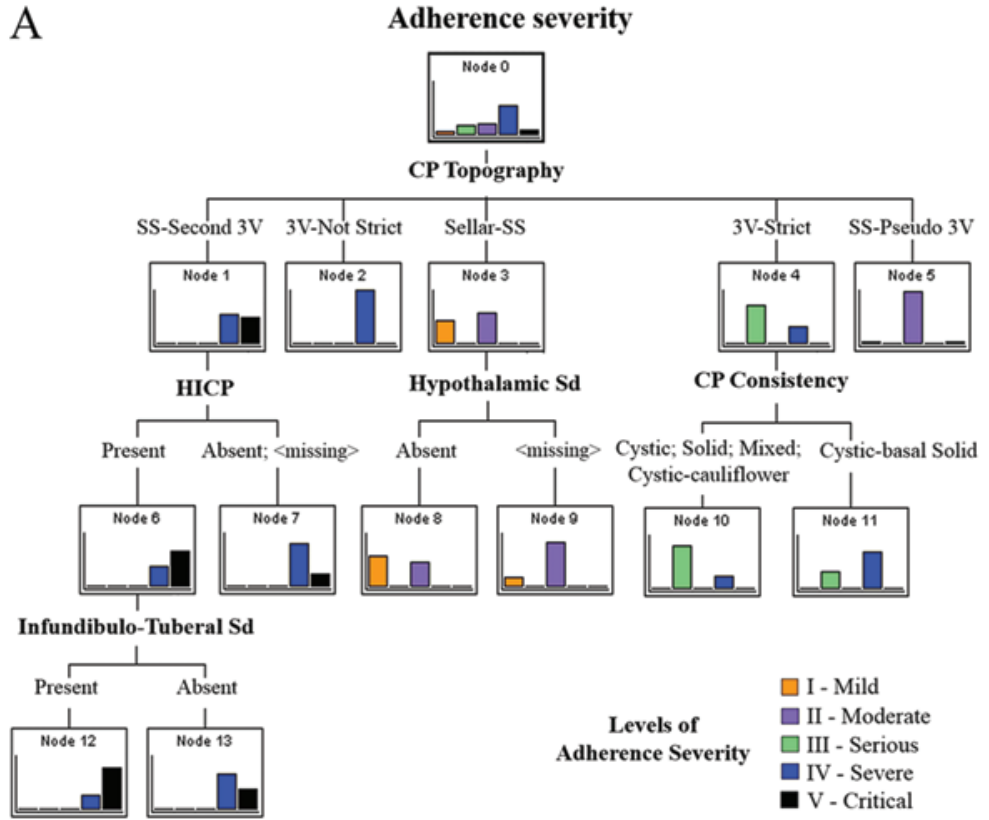

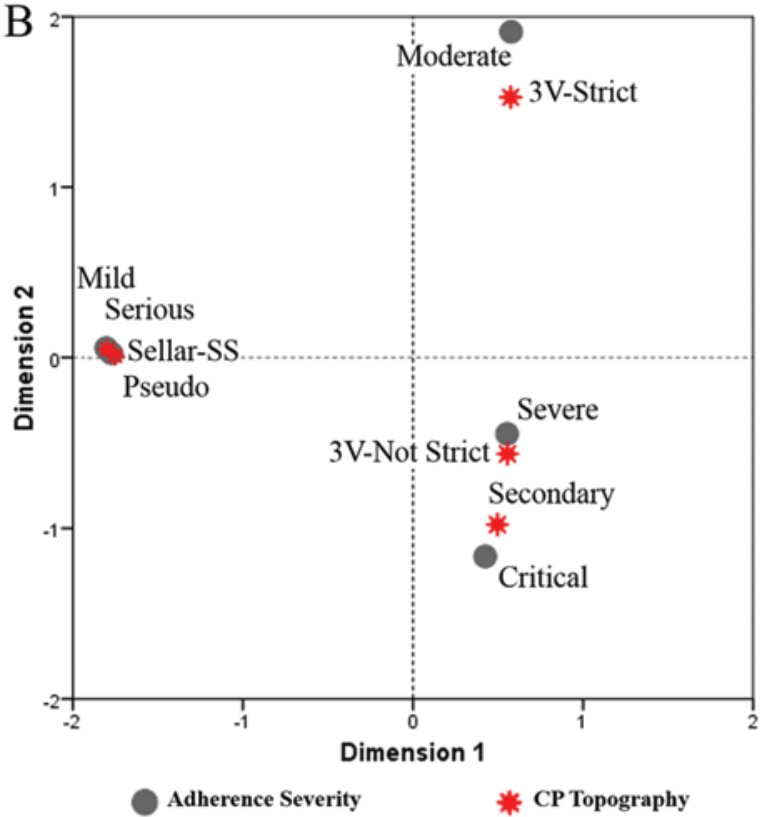

FIG. 7. Multivariate model of adherence severity levels for CPs. A: Growing decision tree generated with a stepwise multivariate hierarchical method of analysis (CHAID). Note that CP topography was chosen in the first step as the fundamental variable to segregate the tumor adherences into 5 nodes, each one corresponding to a different topographical category. Clinical symptoms were included in the second and third steps for the group of suprasellar-secondary intraventricular topography (SS-Second 3V). The rate (probability) for a critical adherence level (black bar) increased from $46 \%$ (Node 1) to 64\% (Node 6) when symptoms of HICP were present and to $76 \%$ (Node 12) when the patient also presented symptoms of the infundibulo-tuberal syndrome. Absence of hypothalamic disturbances increased the probability of the mild adherence level (orange bar) for CPs with sellar-suprasellar topography (Sellar-SS), from $43 \%$ (Node 3) to $56 \%$ (Node 8). The CP consistency was selected in the second step for the strictly intraventicular category (3V-Strict). Presence of a cystic-basal solid consistency increased the percentage of severe adherences (blue bar) from $29 \%$ (Node 4) to $69 \%$ (Node 11). Correct prediction of adherence severity for this multivariate model including the categorical variables CP topography, consistency, and the 3 clinical syndromes (HICP, infundibulo-tuberal, and hypothalamic) reached $87.1 \%$ (see Table 4). B: A 2D plot showing the simple correspondence analysis between CP topography and adherence severity. The correspondence matrix visually displays the strongest associations between CP topographical categories (red stars) and adherence severity levels (gray circles). The variance of adherence severity explained only by CP topography was $73.1 \%$ (see Table 5).

fore the 1950s, correspond to autopsy studies from patients who did not undergo operation, showing the most accurate anatomical evidence regarding the location and extent of $\mathrm{CP}$ adherence; second, the subgroup of lesions treated in the most recent period (1990-2016; MRI-era subcohort) demonstrated essentially the same surgical results as those reported by most large surgical series published for the same period (approximately 5\% mortality and $15 \%$ poor outcome related to hypothalamic injury). The latter result validates the fact that our selection of individual surgical cases is representative of the overall results by experienced surgical teams and largely preserves the learning curve effect on $\mathrm{CP}$ resectability.

\section{Adherence of CPs: A Pathological Feature Related to CP Topography}

Our analysis of the $500 \mathrm{CP}$ cases shows that the TVF (infundibulum and/or tuber cinereum) represents the brain structure predominantly implicated in the $\mathrm{CP}$ attachment in more than half of the cases (54\%). This attachment involves the entire thickness of neural tissue; therefore, it is the most dangerous in terms of the potential iatrogenic injury to the hypothalamus with the dissecting maneuvers required for a radical removal of the lesion. A much more benign type of attachment to the TVF occurs in cases of suprasellar CPs that adhere to an outer aspect (pial surface) of the infundibulum (20\%), or in cases of strictly intraventricular CPs tied to the inner ependymal lining of the $3 \mathrm{~V}(23 \%)$. These results confirm numerous autopsy and surgical observations that have presented evidence that approximately $40 \%$ of CPs grow within the infundibulum and the adjacent TVF and show a strong adherence to these structures..$^{28-38}$

A marked correlation between the morphology of the $\mathrm{CP}$ attachment and the degree of adhesion strength was identified in our analysis. These components depended on the particular location of the tumor and the anatomical structures involved (see Figs. 3 and 4). For example, loose, easily dissectible adhesions commonly occurred between the dome of suprasellar CPs and the outer aspect of the infundibulum. The adhesions, however, were predominantly tight $(60 \%)$ for sessile attachments to either the outer aspect of the infundibulum-PS or to the inner aspect of the TVF. A thin layer of neural tissue fused with the tumor capsule was found in approximately two-thirds of circumferential and bowl-like types of attachment, 
TABLE 4. Classification of adherence severity levels predicted with the multivariate growing method (CHAID) shown in Fig. 7A

\begin{tabular}{lccccccc}
\hline \multirow{2}{*}{$\begin{array}{c}\text { Observed Level } \\
\text { of Severity }\end{array}$} & \multicolumn{4}{c}{ Predicted Level of Adherence Severity } & $\%$ \\
\cline { 2 - 6 } & Mild & Moderate & Serious & Severe & Critical & Correct \\
\hline Mild & 14 & 0 & 4 & 0 & 0 & 77.8 \\
\hline Moderate & 0 & 65 & 0 & 5 & 0 & 92.9 \\
\hline Serious & 11 & 0 & 70 & 0 & 0 & 86.4 \\
\hline Severe & 0 & 18 & 0 & 205 & 6 & 89.5 \\
\hline Critical & 0 & 0 & 1 & 10 & 19 & 63.3 \\
\hline Overall \% & 5.8 & 19.4 & 17.5 & 51.4 & 5.8 & 87.1 \\
\hline
\end{tabular}

Distribution of CPs into the 5 levels of adherence severity predicted with this multivariate model including the categorical variables CP topography, consistency, and 3 clinical syndromes (HICP, infundibulo-tuberal, and hypothalamic). Overall correct prediction of adherence severity reached $87.1 \%$.

which are mostly observed among lesions developed from the TVF. Last, the ring-like type of attachment involved CPs replacing the infundibulo-tuberal region of the TVF in $70 \%$ of cases. These findings fit well with the general agreement in the literature that the area of maximal $\mathrm{CP}$ attachment coincides with the original site of tumor development. $9,12,13,25,31,32,40,42,51,57,59$

One of our crucial results is the strong, significant correlation found between the 3 components of $\mathrm{CP}$ adherence (structure attached, morphology, and degree of adhesion strength) and the tumor topography (Table 1). Usefulness of CP topography to predict the type of CP attachment was validated in the MRI-era subcohort. Sellar-suprasellar and suprasellar pseudointraventricular CPs that developed below an intact TVF most commonly presented with loose to tight, "easily" dissectible adhesions to the PS or to the outer aspect of the infundibulum, either with a sessile or a cap-like morphology. These patterns usually allow a complete and safe removal of the lesion by using gentle, pulling maneuvers. In contrast, the group of originally sellar or suprasellar tumors that invaded the TVF at late stages of development (secondary intraventricular CPs) usually replaced the infundibulo-tuberal region; its remnants were adhered to the central portion of the lesion (ring-like pattern) in $88 \%$ of cases. Finally, a marked difference in the adhesion strength between CPs growing exclusively within the $3 \mathrm{~V}$ cavity and those tumors that developed within the neural layer of the TVF (infundibulo-tuberal lesions) was noticed. "Strict-3V" CPs presented a pedicle or sessile type of attachment to the inner aspect of the $3 \mathrm{~V}$, which spared the anatomical integrity of the TVF and the hypothalamus in almost $70 \%$ of the cases. Conversely, infundibulo-tuberal CPs were characterized by the widest and strongest adhesions to the hypothalamus, with fusion between the neural tissue and central-lower portion of the lesion (bowl-like), or the entire surface (circumferential) of the CP capsule in more than two-thirds of cases. ${ }^{26,28-32,37,46 \text {, }}$ 51,52 The subpial origin of infundibulo-tuberal CPs within the neural tissue of the TVF, above the leptomeningeal layer that covers the pars tuberalis, may well represent the embryological factor determining the circumferential fusion of the tumor capsule to the surrounding brain tissue in the early stages of tumor growth..$^{26,28,46}$
TABLE 5. Correspondence analysis between CP topography and adherence severity shown in Fig. 7B

\begin{tabular}{lrrrrrr}
\hline \multirow{2}{*}{$\begin{array}{c}\text { CP } \\
\text { Topography }\end{array}$} & \multicolumn{5}{c}{ Levels of Adherence Severity } & Active \\
\cline { 2 - 6 } & Mild & Moderate & Serious & Severe & Critical & Margin \\
\hline S-SS & 16 & 0 & 21 & 0 & 0 & 37 \\
\hline SS-pseudo 3V & 2 & 0 & 60 & 0 & 1 & 63 \\
\hline $\begin{array}{l}\text { SS-secondary } \\
\text { 3V }\end{array}$ & 0 & 0 & 0 & 32 & 28 & 60 \\
\hline 3V-not strict & 0 & 0 & 0 & 168 & 1 & 169 \\
\hline 3V-strict & 0 & 70 & 0 & 29 & 0 & 99 \\
\hline Active margin & 18 & 70 & 81 & 229 & 30 & 428 \\
\hline
\end{tabular}

Distribution of cases in each topographical category for the 5 levels of adherence severity. The 2D cumulative proportion of inertia is 0.731 (the correct prediction of adherence severity by considering only the variable $\mathrm{CP}$ topography is $73.1 \%$ ).

\section{Adherence of CPs: A Factor Determining the Surgical Risk of Radical Tumor Removal}

The optimal treatment of CPs remains controversial, with two competing treatment philosophies proposed by different authors: the radical one, which defends the complete excision of the tumor to prevent recurrences and ultimately riskier procedures; ${ }^{15,53,54,59}$ and an alternative, more conservative view that considers a limited, safer resection complemented with radiotherapy or radiosurgery for lesions involving critical vital structures, in particular the hypothalamus. ${ }^{23}$ Invasion of the hypothalamus by a $\mathrm{CP}$ represents the main limitation for a safe total removal of the lesion. The accurate assessment of the type of $\mathrm{CP}$-brain adhesions in each case, in addition to the judicious decision about the feasibility of its safe dissection, are probably the most decisive factors for the successful removal of a CP.

The histological structure of the cleavage plane along the CP-brain adhesions represents an essential pathological aspect to take into account, in particular for lesions attached to the hypothalamus. $18,20,25,31,33,46,49,51$ Almost every single study analyzing the $\mathrm{CP}$-brain interface has observed "finger-shaped" protrusions or "island-like" clusters of tumor cells growing into the adjacent brain tissue. They are considered the histological substrate of brain invasion. ${ }^{1,2,4,15,16,18,20,25,31,49,50,54,60} \mathrm{In}$ the present analysis, tumor projections into the hypothalamus were observed mainly in CPs presenting a ring-like band of attachment to the TVF and the lower $3 \mathrm{~V}$ walls. Most of the lesions showing brain invasion were either infundibulo-tuberal CPs that originally developed at a subpial position within the TVF, or suprasellar tumors that invaded the $3 \mathrm{~V}$ after breaking the TVF (secondary intraventricular CPs). Brain invasion was not observed, as a rule, among suprasellar CPs that did not disrupt the pial cover over the TVF.

The development of the tumor within the neural tissue of the TVF, above the pia mater that covers the tuber cinereum, seems to induce a strong reactive gliosis around the tumor, a pathological feature proposed as a major cause of the firm adherence in lesions with this topography. $2,7,8,18,20,25,31,40,45,50-52,54,59,60$ Our study confirms that this layer of reactive gliosis, forming the cleavage plane be- 
tween the tumor and brain tissue, is a feature typically observed in the circumferential and ring-like types of attachment, usually observed in infundibulo-tuberal CPs that are fused to or replacing the TVF (Table 1). Some authors assume that this "glial envelope" may serve as a safety margin for resection..$^{15,53}$ The reactive gliosis, however, did not envelop the entire lesion in all cases. Direct contact between finger-like tumor extensions and the hypothalamic nuclei has been evidenced in many cases of this cohort, representing the major obstacle to a complete, safe tumor removal. $2,4,16,31,49,51,54,59$

Overall, surgery-related mortality in this series of 500 well-described CPs reached 30\%, and an additional 15\% of patients suffered severe sequelae derived for the most part from hypothalamic injury. The highest perioperative morbidity and mortality was observed for CPs attached to the TVF and the $3 \mathrm{~V}$ walls (Fig. 6A and D). The analysis of adherence components-related outcome showed an apparent linear relationship between a more extensive and stronger $\mathrm{CP}$ attachment and a worse postoperative outcome. The morbidity and mortality rate increased for the ring-like, bowl-like, and circumferential patterns as well as for the fused and replacement types of adhesion strength (Fig. 6B and C). These latter types of $\mathrm{CP}$ adherence usually involve the hypothalamus, their dissection requiring a perfect view of the $\mathrm{CP}$-brain cleavage plane and very delicate handling of the nonfunctional gliotic tissue interposed between the tumor and the hypothalamus. The high morbidity and mortality rate observed after radical resection of CPs invading the infundibulo-tuberal area is related to the hypothalamic injury accompanying attempts to separate the strong adhesions between the tumor and the hypothalamus, a result supporting the decision to limit the tumor resection in these CP adhesions.

It could be argued that our conclusions from the analysis of a retrospective cohort formed by individual CPs leaves out certain key surgical factors related to outcome, mainly the expertise on dealing with $\mathrm{CP}$ adherences gained with training and linked to the learning curve. For this reason, we have compared the data from the subgroup of cases that we treated in the period between 1990 and 2016 (MRI-era subcohort, $\mathrm{n}=225$ ) with the cases reported in large surgical CP series in the literature of the last 2 decades. ${ }^{6,10,11,14,21 \text {, }}$ 22,24,27,46,48,52,55-57,59 The perioperative death rate in our MRIera subcohort was $5 \%$, an almost identical rate compared with the reported rate in recent surgical series. ${ }^{34}$ Poor postoperative outcome due to hypothalamic injury occurred in $15 \%$ of patients of the MRI-era subcohort, a figure very close to that reported among large surgical series (from $5 \%$ to $20 \%$ depending on the series). Similar death and poor outcome rates must be appreciated within the context of an even higher rate of gross-total removal in our MRI subcohort $(75 \%)$ than the reported rate among large surgical series for the last 2 decades (55\% on average). Besides, the same linear relationship between a worse outcome and a more extensive and stronger type of adherence was observed in the subgroup of CPs treated after 1990 than in the global cohort (Fig. 6). Therefore, the influence that the CP adherence categories, defined from our whole cohort, has on surgical outcome should be considered fully representative of the most recent large surgical series.
In addition to the technical and therapeutic advances in recent decades, surgical expertise has proven that the resection of tight $\mathrm{CP}$ adherences to the hypothalamus without patient death is possible in many cases. ${ }^{11,14,17,55}$ However, the morbidity associated with permanent hypothalamic dysfunction after the gross removal of CPs involving the TVF-3V is still high and surely underestimated, because of the insufficient assessment of long-term symptoms related to hypothalamic injury. ${ }^{11,24,55-57}$ The preoperative clinical status has been shown to have a more important impact on the functional outcome of CP surgery than the surgeon's experience, a finding that supports the great influence that pathological factors such as tumor topography and adherence may have on the surgical outcome. ${ }^{41,43,58}$ The patients at the greatest risk of surgery-related hypothalamic injury are those with preoperative hypothalamic symptoms, such as psychiatric disturbances and/or severe memory defects, which are typical of intraventricular CPs showing the strongest (fusion/replacement) and more extensive (circumferential/ring-like/bowl-like) types of attachment. ${ }^{3,11,12,18,19,47,59}$ Overall, our findings highlight the high risk associated with indiscriminate attempts at total removal of infundibulo-tuberal and secondary intraventricular CPs that are fused to the TVF or have replaced it, and present a circumferential or ring-like attachment to the hypothalamus.

\section{Levels of CP Adherence Severity: A Grading System With Impact on Surgical Outcome}

The level of $\mathrm{CP}$ adherence stands out as a fundamental surgical variable influencing the patient outcome. The accurate assessment of $\mathrm{CP}$ adherence should represent the essential information dictating the decision about a reasonable degree of tumor removal to be attempted..$^{33,40,43} \mathrm{In}$ this study a grading system of CP adherence that considers 5 increasing levels of adherence severity is proposed, depending on the location of the attachment, its morphology, and the strength of the bond. This model proved to be a valid method to stratify the surgical risks associated with radical removal of CPs. It showed an excellent correlation with the surgical outcome when tested on the CPs in our cohort, which encompasses surgical procedures performed by various experts throughout the last century (Table 3). The 5 levels of $\mathrm{CP}$ adherence severity would be characterized as follows.

\section{Level I-Mild Adherence}

A mild CP adherence (Level I adherence severity) is assigned to pure intrasellar or sellar-suprasellar tumors usually originating at the junction of the PG with the PS and separated from the TVF by the dura mater of the diaphragma sellae and/or a layer of arachnoid membrane. A satisfactory postoperative outcome was the rule for this subgroup of lesions, with no morbidity or mortality derived from hypothalamic injury, a fact most likely related to the shielding effect of the meningeal layer interposed between the dome of the tumor and the hypothalamus.

\section{Level II-Moderate Adherence}

The group of CPs with moderate adherence (Level II) includes the strictly intraventricular tumors showing 
a pedicle or sessile attachment to the inner aspect of the $3 \mathrm{~V}$. The resection of these tumors was associated with a poor outcome or caused the death of the patient in $22.5 \%$ of cases. This significant increase of surgical risk cannot be attributed only to the morphology and degree of the attachment, which is usually released straightforwardly. Complications related to the complex surgical approaches required to remove these lesions and the vulnerability of the anatomical structures in proximity to the $3 \mathrm{~V}$ are also responsible for the increased risk.

\section{Level III-Serious Adherence}

Serious CP adherence (Level III) comprises those suprasellar CPs attached to the pial surface of the infundibulum and/or tuber cinereum, without an intervening arachnoid layer. The sum of poor outcomes and mortalities was approximately $30 \%$ among these lesions, due to the substantial damage to the median eminence and basal hypothalamus by the dissecting maneuvers aimed to release the tumor capsule from its attachment.

\section{Level IV_Severe Adherence}

Severe CP adherence (Level IV) involves CPs presenting with wide and tenacious adhesions to the TVF and lower half of the $3 \mathrm{~V}$ walls, with a bowl-like, ring-like, or a circumferential morphology. Mortality rates notably increased after removal of these tumors. Approximately $37 \%$ of patients died shortly after surgery, and an additional $20 \%$ suffered from disabling permanent hypothalamic disorders. The majority of these lesions corresponded to infundibulo-tuberal CPs that developed from subpial remnants of Rathke's pouch within the TVF. The presence of finger-like tumor protrusions across the $\mathrm{CP}-$ brain interface along the cleavage plane that come into contact with the hypothalamic nuclei accounts for the high morbidity and mortality observed after the removal of these lesions.

\section{Level V-Critical Adherence}

The category of most severe or critical CP adherence (Level V) is assigned for those tumors presenting multiple and/or broad attachments to all the structures along the vertical hypothalamic-pituitary axis, including the PG, the PS, the TVF, and the $3 \mathrm{~V}$ walls. The removal of these generally giant, solid-cystic CPs was associated with $50 \%$ mortality and poor outcomes of $60 \%$ among surviving patients. The daunting outcome associated with these lesions can be explained by their biologically aggressive behavior, because they tend to encroach on the anatomical structures along the path of development, and these structures usually become replaced by tumor tissue.

Surgery of CPs involving the hypothalamus is associated with morbidity and mortality rates that are 3 times higher than those for sellar-suprasellar CPs. ${ }^{29,31}$ In the present study, the mortality rate due to hypothalamic injury during surgery was the highest for the circumferential and ring-like patterns of attachment to the TVF-3V (34\%) as well as for the most severe degrees of adhesion strength (42\% among CPs fused to the TVF or replacing this structure). To avoid these fatal complications, it has been recommended that portions of the tumor presenting the stron- gest attachment to the TVF-3V walls be left untouched, a surgical philosophy that has been implemented over the last 2 decades in many neurosurgical departments..$^{14,23,39}$ The stratification scheme proposed for levels of severity adherence should be incorporated for an appropriate individualized evaluation of the surgical risk and outcome associated with the removal of CPs.

\section{Conclusions}

A comprehensive description of $\mathrm{CP}$ adherence is necessary to anticipate the surgical risk of hypothalamic injury and to plan the degree of removal accordingly. The definition of CP adherence should include a description of the neural structures attached to the tumor and the morphology or extent of the attachment as well as its strength. A descriptive model of CP adherence, taking into account the above-mentioned variables, provides a useful tool for an adequate characterization of the $\mathrm{CP}-$ brain cleavage plane, allowing a better assessment of the risks associated with a radical removal. The CP topography is the fundamental variable in predicting the type of tumor adhesion. This information, in addition to the tumor consistency and the type of clinical manifestations, can be used with reasonable accuracy to preoperatively predict the specific pattern and strength of adherence of an individual $\mathrm{CP}$.

\section{Acknowledgments}

We especially thank Crystal Smith and Liliya Gusakova, reference librarians at the National Library of Medicine, NIH (Bethesda, MD), for their kind assistance during the process of searching and retrieving articles and monographs used in this study. We are indebted to Bill Landis and all the staff of the Manuscript and Archives Department of the Sterling Memorial Library at Yale University (New Haven, CT) for their kind assistance in accessing the Cushing's Brain Tumor Registry. We are also grateful to Melissa Grafe, librarian at the Medical History Library at Yale University (New Haven, CT) and Jack Eckert and the staff at the Francis Countway Medical Library at Harvard Medical School (Boston, MA) for their invaluable help in obtaining some of the original research material used for this study. Finally, we are grateful to George Hamilton for his critical review of the language and style of the manuscript.

\section{References}

1. Adamson TE, Wiestler OD, Kleihues P, Yaşargil MG: Correlation of clinical and pathological features in surgically treated craniopharyngiomas. J Neurosurg 73:12-17, 1990

2. Bailey P, Buchanan DN, Bucy PC: Craniopharyngiomas, in Intracranial Tumors of Infancy and Childhood. Chicago: University of Chicago Press, 1939, pp 349-375

3. Bosnjak R, Benedicic M, Vittori A: Early outcome in endoscopic extended endonasal approach for removal of supradiaphragmatic craniopharyngiomas: a case series and a comprehensive review. Radiol Oncol 47:266-279, 2013

4. Burger PC, Scheithauer BW, Vogel FS: Region of the sella turcica. Craniopharyngiomas, in: Surgical Pathology of the Nervous System and Its Coverings, ed 4. New York: Churchill Livingstone, 2002, pp 475-483

5. Castro-Dufourny I, Carrasco R, Prieto R, Barrios L, Pascual JM: The infundibulo-tuberal syndrome caused by craniopharyngiomas: clinicopathological evidence from an historical French cohort (1705-1973). Pituitary 18:642-657, 2015 
6. Cavallo LM, Solari D, Esposito F, Cappabianca P: The endoscopic endonasal approach for the management of craniopharyngiomas involving the third ventricle. Neurosurg Rev 36:27-38, 2013

7. Ciric IS, Cozzens JW: Craniopharyngiomas: transsphenoidal method of approach - for the virtuoso only? Clin Neurosurg 27:169-187, 1980

8. Critchley M, Ironside RN: The pituitary adamantinomata. Brain 49:437-481, 1926

9. Cushing H: Congenital tumors: the craniopharyngiomas, in Intracranial Tumors. Notes upon a series of two thousand verified cases with surgical-mortality percentages pertaining thereto. Springfield, IL: Charles C Thomas, 1932, pp 93-104

10. de Divitiis E, Cappabianca P, Cavallo LM, Esposito F, de Divitiis O, Messina A: Extended endoscopic transsphenoidal approach for extrasellar craniopharyngiomas. Neurosurgery 61(ONS Suppl 2):ONS219-ONS228, 2007

11. De Vile CJ, Grant DB, Kendall BE, Neville BG, Stanhope R, Watkins KE, et al: Management of childhood craniopharyngioma: can the morbidity of radical surgery be predicted? J Neurosurg 85:73-81, 1996

12. Dott NM: Surgical aspects of the hypothalamus, in Le Gros Clark WE, Beattie J, Riddoch G, et al (eds): The Hypothalamus, Morphological, Functional, Clinical and Surgical Aspects. Edinburgh: Oliver and Boyd, 1938, pp 131-185

13. Erdheim J: Über Hypophysengangsgeschwülste und Hirncholesteatome. Sitzungsb Kais Akad Wissen Math Naturw Klin 113:537-726, 1904

14. Fahlbusch R, Honegger J, Paulus W, Huk W, Buchfelder M: Surgical treatment of craniopharyngiomas: experience with 168 patients. J Neurosurg 90:237-250, 1999

15. Hoffman HJ, De Silva M, Humphreys RP, Drake JM, Smith ML, Blaser SI: Aggressive surgical management of craniopharyngiomas in children. J Neurosurg 76:47-52, 1992

16. Kahn EA: Tumors of the sellar region, in Kahn EA, Bassett RC, Schneider RC, et al (eds): Correlative Neurosurgery. Springfield: Charles C Thomas, 1955, pp 168-190

17. Kassam AB, Gardner PA, Snyderman CH, Carrau RL, Mintz AH, Prevedello DM: Expanded endonasal approach, a fully endoscopic transnasal approach for the resection of midline suprasellar craniopharyngiomas: a new classification based on the infundibulum. J Neurosurg 108:715-728, 2008

18. Kobayashi T, Kageyama N, Yoshida J, Shibuya N, Yonezawa T: Pathological and clinical basis of the indications for treatment of craniopharyngiomas. Neurol Med Chir (Tokyo) 21:39-47, 1981

19. Konovalov AN: Operative management of craniopharyngiomas. Adv Tech Stand Neurosurg 8:281-318, 1981

20. Kubota T, Yamamoto S, Kohno H, Ito H, Hayashi M: [Operative procedures of craniopharyngioma estimated by autopsy findings (author's transl).] Neurol Med Chir (Tokyo) 20:341-354, 1980 (Jpn)

21. Maira G, Anile C, Colosimo C, Cabezas D: Craniopharyngiomas of the third ventricle: trans-lamina terminalis approach. Neurosurgery 47:857-865, 2000

22. Maira G, Anile C, Rossi GF, Colosimo C: Surgical treatment of craniopharyngiomas: an evaluation of the transsphenoidal and pterional approaches. Neurosurgery 36:715-724, 1995

23. Meuric S, Brauner R, Trivin C, Souberbielle JC, Zerah M, Sainte-Rose C: Influence of tumor location on the presentation and evolution of craniopharyngiomas. J Neurosurg 103 (5 Suppl Pediatrics): 421-426, 2005

24. Mortini P, Losa M, Pozzobon G, Barzaghi R, Riva M, Acerno $S$, et al: Neurosurgical treatment of craniopharyngioma in adults and children: early and long-term results in a large case series. J Neurosurg 114:1350-1359, 2011

25. Northfield DWC: Rathke-pouch tumours. Brain 80:293-312, 1957
26. Pan J, Qi S, Liu Y, Lu Y, Peng J, Zhang X, et al: Growth patterns of craniopharyngiomas: clinical analysis of 226 patients. J Neurosurg Pediatr 17:418-433, 2016

27. Pan J, Qi S, Lu Y, Fan J, Zhang X, Zhou J, et al: Intraventricular craniopharyngioma: morphological analysis and outcome evaluation of 17 cases. Acta Neurochir (Wien) 153:773-784, 2011

28. Pascual JM, Carrasco R, Prieto R, Gonzalez-Llanos F, Alvarez F, Roda JM: Craniopharyngioma classification. J Neurosurg 109:1180-1183, 2008

29. Pascual JM, González-Llanos F, Barrios L, Roda JM: Intraventricular craniopharyngiomas: topographical classification and surgical approach selection based on an extensive overview. Acta Neurochir (Wien) 146:785-802, 2004

30. Pascual JM, Prieto R: Harvey Cushing and pituitary Case Number 3 (Mary D.): the origin of this most baffling problem in neurosurgery. Neurosurg Focus 41(1):E6, 2016

31. Pascual JM, Prieto R, Carrasco R: Infundibulo-tuberal or not strictly intraventricular craniopharyngioma: evidence for a major topographical category. Acta Neurochir (Wien) 153:2403-2426, 2011

32. Pascual JM, Prieto R, Carrasco R, Barrios L: Displacement of mammillary bodies by craniopharyngiomas involving the third ventricle: surgical-MRI correlation and use in topographical diagnosis. J Neurosurg 119:381-405, 2013

33. Pascual JM, Prieto R, Carrasco R, Castro-Dufourny I, Barrios L: Craniopharyngioma adherence to the hypothalamus. Neurosurg Focus 37(2):1-9, 2014 (Letter)

34. Pascual JM, Prieto R, Carrasco R, Castro-Dufourny I, Strauss S, Gil-Simoes R, et al: Premio Sixto Obrador 2013. Modelo topográfico de 3 ejes para el tratamiento quirúrgico de los craneofaringiomas. Parte II: Evidencias anatómicas y neurorradiológicas que definen el modelo de clasificación de 3 ejes y su utilidad para predecir el riesgo quirúrgico individual. Neurocirugia (Astur) 25:211-239, 2014

35. Pascual JM, Prieto R, Castro-Dufourny I, Carrasco R, Strauss S, Barrios L: Development of intracranial approaches for craniopharyngiomas: an analysis of the first 160 historical procedures. Neurosurg Focus 36(4):E13, 2014

36. Pascual JM, Prieto R, Mazzarello P: Sir Victor Horsley: pioneer craniopharyngioma surgeon. J Neurosurg 123:39-51, 2015

37. Pascual JM, Prieto R, Navas M, Carrasco R: Conquest of third ventricle craniopharyngiomas. J Neurosurg 112:11561161 , author reply 1161,2010

38. Pascual JM, Rosdolsky M, Prieto R, Strau $\beta$ S, Winter E, Ulrich W: Jakob Erdheim (1874-1937): father of hypophyseal-duct tumors (craniopharyngiomas). Virchows Arch 467:459-469, 2015

39. Pierre-Kahn A, Recassens C, Pinto G, Thalassinos C, Chokron S, Soubervielle JC, et al: Social and psycho-intellectual outcome following radical removal of craniopharyngiomas in childhood. A prospective series. Childs Nerv Syst 21:817824, 2005

40. Prieto R, Castro-Dufourny I, Carrasco R, Barrios L, Pascual JM: Craniopharyngioma recurrence: the impact of tumor topography. J Neurosurg 125:1043-1049, 2016

41. Prieto R, Pascual JM: Accurate craniopharyngioma topography for patient outcome improvement. World Neurosurg 82:e555-e559, 2014

42. Prieto R, Pascual JM: Craniopharyngiomas with a mixed histological pattern: the missing link to the intriguing pathogenesis of adamantinomatous and squamous-papillary varieties? Neuropathology 33:682-686, 2013

43. Prieto R, Pascual JM: Norman M. Dott, master of hypothalamic craniopharyngioma surgery: the decisive mentoring of Harvey W. Cushing and Percival Bailey at Peter Bent Brigham Hospital. J Neurosurg [in press], 2016

44. Prieto R, Pascual JM, Barrios L: Optic chiasm distortions 
caused by craniopharyngiomas: clinical and magnetic resonance imaging correlation and influence on visual outcome. World Neurosurg 83:500-529, 2015

45. Prieto R, Pascual JM, Subhi-Issa I, Jorquera M, Yus M, Martínez R: Predictive factors for craniopharyngioma recurrence: a systematic review and illustrative case report of a rapid recurrence. World Neurosurg 79:733-749, 2013

46. Qi S, Lu Y, Pan J, Zhang X, Long H, Fan J: Anatomic relations of the arachnoidea around the pituitary stalk: relevance for surgical removal of craniopharyngiomas. Acta Neurochir (Wien) 153:785-796, 2011

47. Rougerie J, Fardeau M: Étude histopathologique, in Les cranio-pharyngiomes. Paris: Masson et Cie, 1962, pp 22-31

48. Shi XE, Wu B, Fan T, Zhou ZQ, Zhang YL: Craniopharyngioma: surgical experience of 309 cases in China. Clin Neurol Neurosurg 110:151-159, 2008

49. Shillito J Jr: Craniopharyngiomas: the subfrontal approach, or none at all? Clin Neurosurg 27:188-205, 1980

50. Steno J: Craniopharyngiomas and suprasellar tumors, in Ellenbogen RG, Abdulrauf SI, Sekhar LN (eds): Principles of Neurological Surgery, ed 3. Philadelphia: Elsevier Saunders, 2013, pp 597-620

51. Steno J: Microsurgical topography of craniopharyngiomas. Acta Neurochir Suppl (Wien) 35:94-100, 1985

52. Steno J, Malácek M, Bízik I: Tumor-third ventricular relationships in supradiaphragmatic craniopharyngiomas: correlation of morphological, magnetic resonance imaging, and operative findings. Neurosurgery 54:1051-1060, 2004

53. Sweet WH: Craniopharyngiomas, with a note on Rathke's cleft or epithelial cyst and on suprasellar cysts, in Schmidek HH, Sweet WH (eds): Operative Neurosurgical Techniques, Indications, Methods and Results, ed 2. New York: Grune \& Stratton, 1988, pp 291-325

54. Sweet WH: History of surgery for craniopharyngiomas. Pediatr Neurosurg 21 (Suppl 1):28-38, 1994

55. Tomita T, Bowman RM: Craniopharyngiomas in children: surgical experience at Children's Memorial Hospital. Childs Nerv Syst 21:729-746, 2005

56. Van Effenterre R, Boch AL: Craniopharyngioma in adults and children: a study of 122 surgical cases. J Neurosurg 97:3-11, 2002
57. Wang KC, Kim SK, Choe G, Chi JG, Cho BK: Growth patterns of craniopharyngioma in children: role of the diaphragm sellae and its surgical implication. Surg Neurol 57:25-33, 2002

58. Wisoff JH, Elliott RE: Craniopharyngioma. Radical resection, in Jallo GI, Kothbauer KF, Pradilla G (eds): Controversies in Pediatric Neurosurgery. New York: Thieme, 2010, pp 63-70

59. Yaşargil MG: Craniopharyngiomas, in Microneurosurgery. Stuttgart: Thieme, 1996, Vol 4B, pp 205-223

60. Zülch KJ: Pineal and pituitary glands, craniopharyngeal duct: the craniopharyngiomas (hypophyseal duct tumors, Erdheim tumors, adamantinoma of pituitary region), in Atlas of Gross Neurosurgical Pathology. Berlin: Springer, 1975, pp $155-160$

\section{Disclosures}

The authors report no conflict of interest concerning the materials or methods used in this study or the findings specified in this paper.

\section{Author Contributions}

Conception and design: Prieto, Pascual. Acquisition of data: Prieto, Pascual, Castro-Dufourny, Carrasco, Strauss. Analysis and interpretation of data: Prieto, Pascual. Drafting the article: Prieto, Pascual, Rosdolsky. Critically revising the article: Prieto, Pascual, Rosdolsky. Reviewed submitted version of manuscript: all authors. Approved the final version of the manuscript on behalf of all authors: Prieto. Statistical analysis: Barrios.

\section{Supplemental Information}

\section{Online-Only Content}

Supplemental material is available with this article.

Supplemental Table and Reference List. https://thejns.org/doi/ suppl/10.3171/2016.9.FOCUS16304.

\section{Correspondence}

Ruth Prieto, Department of Neurosurgery, Puerta de Hierro University Hospital, C/Joaquín Rodrigo 2, Majadahonda, Madrid 28222, Spain.email: rprieto29@hotmail.com. 